\title{
Ship noise extends to frequencies used for echolocation by endangered killer whales
}

Scott Veirs, Val Veirs, Jason D Wood

Combining calibrated hydrophone measurements with vessel location data from the Automatic Identification System, we estimate underwater sound pressure levels for 1,582 unique ships that transited the core critical habitat of the endangered Southern Resident killer whales during 28 months between March, 2011, and October, 2013. Median received spectrum levels of noise from 2,809 isolated transits are elevated relative to median background levels not only at low frequencies (20-30 dB re $1 \mu \mathrm{Pa}^{2} / \mathrm{Hz}$ from 100-1000 Hz), but also at high frequencies ( $5-13 \mathrm{~dB}$ from $10,000-96,000 \mathrm{~Hz}$ ). Thus, noise received from ships at ranges less than $3 \mathrm{~km}$ extends to frequencies used by odontocetes. Broadband received levels $(11.5-40,000 \mathrm{~Hz})$ near the shoreline in Haro Strait (WA, USA) for the entire ship population were $110 \pm 7 \mathrm{~dB}$ re $1 \mu \mathrm{Pa}$ on average. Assuming near-spherical spreading based on a transmission loss experiment we compute mean broadband source levels for the ship population of $173 \pm 7 \mathrm{~dB}$ re $1 \mu \mathrm{Pa} @ 1 \mathrm{~m}$ without accounting for frequencydependent absorption. Mean ship speed was $7.3 \pm 2.0 \mathrm{~m} / \mathrm{s}$ (14.1 \pm 3.9 knots). Most ship classes show a linear relationship between source level and speed with a slope near $+2 \mathrm{~dB}$ per $\mathrm{m} / \mathrm{s}$ ( $+1 \mathrm{~dB} / \mathrm{knot}$ ). Spectrum, 1/12-octave, and 1/3-octave source levels for the whole population have median values that are comparable to previous measurements and models at most frequencies, but for select studies may be relatively low below $200 \mathrm{~Hz}$ and high above 20,000 Hz. Median source spectrum levels peak near $50 \mathrm{~Hz}$ for all 12 ship classes, have a maximum of $159 \mathrm{~dB}$ re $1 \mu \mathrm{Pa}^{2} / \mathrm{Hz} @ 1$ for container ships, and vary between classes. Below $200 \mathrm{~Hz}$, the class-specific median spectrum levels bifurcate with large commercial ships grouping as higher power noise sources. Within all ship classes spectrum levels vary more at low frequencies than at high frequencies, and the degree of variability is almost halved for classes that have smaller speed standard deviations. This is the first study to present source spectra for populations of different ship classes operating in coastal habitats, including at higher frequencies used by killer whales for both communication and echolocation. 


\title{
Ship noise extends to frequencies used for
}

\section{echolocation by endangered killer whales}

\author{
Scott Veirs ${ }^{1}$, Val Veirs ${ }^{2}$, and Jason Wood ${ }^{3}$ \\ ${ }^{1}$ Beam Reach Marine Science and Sustainability School, Seattle, WA, USA; \\ scott@beamreach.org; corresponding author \\ ${ }^{2}$ Colorado College, Department of Physics, Colorado Springs, CO, USA; \\ vveirs@coloradocollege.edu \\ ${ }^{3}$ SMRU Consulting, Friday Harbor, WA, USA.; jw@smruconsulting.com
}

\begin{abstract}
Combining calibrated hydrophone measurements with vessel location data from the Automatic Identification System, we estimate underwater sound pressure levels for 1,582 unique ships that transited the core critical habitat of the endangered Southern Resident killer whales during 28 months between March, 2011 , and October, 2013. Median received spectrum levels of noise from 2,809 isolated transits are elevated relative to median background levels not only at low frequencies $\left(20-30 \mathrm{~dB}\right.$ re $1 \mu \mathrm{Pa}^{2} / \mathrm{Hz}$ from $100-1000 \mathrm{~Hz}$ ), but also at high frequencies $(5-13 \mathrm{~dB}$ from $10,000-96,000 \mathrm{~Hz})$. Thus, noise received from ships at ranges less than $3 \mathrm{~km}$ extends to frequencies used by odontocetes. Broadband received levels $(11.5-40,000 \mathrm{~Hz})$ near the shoreline in Haro Strait (WA, USA) for the entire ship population were $110 \pm 7 \mathrm{~dB}$ re $1 \mu \mathrm{Pa}$ on average. Assuming near-spherical spreading based on a transmission loss experiment we compute mean broadband source levels for the ship population of $173 \pm 7 \mathrm{~dB}$ re $1 \mu \mathrm{Pa} @ 1 \mathrm{~m}$ without accounting for frequency-dependent absorption. Mean ship speed was $7.3 \pm 2.0 \mathrm{~m} / \mathrm{s}$ (14.1 $\pm 3.9 \mathrm{knots})$. Most ship classes show a linear relationship between source level and speed with a slope near $+2 \mathrm{~dB}$ per $\mathrm{m} / \mathrm{s}$ ( $+1 \mathrm{~dB} / \mathrm{knot})$. Spectrum, 1/12-octave, and 1/3-octave source levels for the whole population have median values that are comparable to previous measurements and models at most frequencies, but for select studies may be relatively low below $200 \mathrm{~Hz}$ and high above $20,000 \mathrm{~Hz}$. Median source spectrum levels peak near $50 \mathrm{~Hz}$ for all 12 ship classes, have a maximum of $159 \mathrm{~dB}$ re $1 \mu \mathrm{Pa}^{2} / \mathrm{Hz} @ 1 \mathrm{~m}$ for container ships, and vary between classes. Below $200 \mathrm{~Hz}$, the class-specific median spectrum levels bifurcate with large commercial ships grouping as higher power noise sources. Within all ship classes spectrum levels vary more at low frequencies than at high frequencies, and the degree of variability is almost halved for classes that have smaller speed standard deviations. This is the first study to present source spectra for populations of different ship classes operating in coastal habitats, including at higher frequencies used by killer whales for both communication and echolocation.
\end{abstract}

Keywords: noise, ship, hydrophone, killer whale, orca, odontocete, marine mammal 


\section{INTRODUCTION}

Commercial ships radiate noise underwater with peak spectral power at 20-200 Hz (Ross, 1976). Ship noise is generated primarily from propeller cavitation, propeller singing, and propulsion or other reciprocating machinery (Richardson et al., 1995; Wales and Heitmeyer, 2002; Hildebrand, 2009). The dominant noise source is usually propeller cavitation which has peak power near $50-150 \mathrm{~Hz}$ (at blade rates and their harmonics), but also radiates broadband power at higher frequencies, at least up to $100,000 \mathrm{~Hz}$ (Ross, 1976; Gray and Greeley, 1980; Arveson and Vendittis, 2000). While propeller singing is caused by blades resonating at vortex shedding frequencies and emits strong tones between 100 and $1000 \mathrm{~Hz}$, propulsion noise is caused by shafts, gears, engines, and other machinery and has peak power below $50 \mathrm{~Hz}$ (Richardson et al., 1995). Overall, larger vessels generate more noise at low frequencies $(<1,000 \mathrm{~Hz})$ because of their relatively high power, deep draft, and slower-turning $(<250 \mathrm{rpm})$ engines and propellers (Richardson et al., 1995).

This low-frequency energy from ships is the principal source of ambient noise within the deep ocean from approximately 5-1,000 Hz (Wenz, 1962; Urick, 1983; National Research Council et al., 2003). Growth of the global shipping fleet and possibly the average size of ships has raised deep-ocean ambient noise levels in low-frequency bands near $40 \mathrm{~Hz}$ by up to $20 \mathrm{~dB}$ relative to pre-industrial conditions (Hildebrand, 2009) and 8-10 dB since the 1960s (Andrew et al., 2002; McDonald et al., 2006).

As these ships enter shallow waters and traverse the estuarine habitat typically occupied by major ports, the noise they radiate may impact coastal marine life. Since many marine mammals rely on sound to find prey, moderate social interactions, and facilitate mating (Tyack, 2008), noise from anthropogenic sound sources like ships can interfere with these functions, but only if the noise spectrum overlaps with the hearing sensitivity of the marine mammal (Southall et al., 2007; Clark et al., 2009; Hatch et al., 2012).

Hearing sensitivity isn't yet characterized in Mysticetes (baleen whales), but based on their signals they are likely most sensitive at frequencies $10-10,000 \mathrm{~Hz}$ and therefore constitute a low-frequency functional hearing group (Southall et al., 2007). They typically emit signals with fundamental frequencies well below 1,000 Hz (Cerchio et al., 2001; Au et al., 2006; Munger et al., 2008) although non-song humpback signals have peak power near 800 and 1,700 Hz (Stimpert, 2010) and humpback song harmonics extend up to $24,000 \mathrm{~Hz}$ (Au et al., 2006).

The frequency overlap of peak power in ship noise and baleen whale signals (and inferred maximum hearing sensitivity) is verified by observed behavioral and physiological responses of mysticetes to ship noise. As examples, the probability of detecting a blue whale D call increases in ship noise, suggesting a Lombard effect (Melcon et al., 2012) and Rolland et al. (2012) found decreased stress levels in North Atlantic right whales when ship noise was absent. 
The potential impacts of ship noise can be assessed more confidently in Odontocetes (toothed whales) because they constitute mid-frequency or high-frequency functional hearing groups (Southall et al., 2007) in which auditory response curves have been obtained for many species. These curves show maximum auditory sensitivity near the frequencies where toothed whale signals have peak power (Mooney et al., 2012; Tougaard et al., 2014) - at about 1,000-20,000 Hz for social sounds and 10,000-100,000 Hz or higher for echolocation.

Southern Resident killer whales (SRKWs) represent an endangered toothed whale species that inhabits an urban estuary in which shipping traffic is common and is very well characterized bioacoustically. Their auditory sensitivity, extrapolated from captive killer whales (Hall and Johnson, 1972; Szymanski et al., 1999), peaks at $15,000-20,000 \mathrm{~Hz}$ - a frequency range that overlaps with the upper range of their vocalizations and the lower range of their echolocation clicks. SRKW calls have fundamental frequencies at $100-6,000 \mathrm{~Hz}$ with harmonics extending up to $30,000 \mathrm{~Hz}$ (Ford, 1987). Their echolocation clicks are likely similar to those of salmon-eating northern resident killer whales which have a 40,000 $\mathrm{Hz}$ bandwidth and a mean center frequency of 50,000 Hz (Au et al., 2004). SRKWs whistle between 2,000 and $16,000 \mathrm{~Hz}$ (Riesch et al., 2006) with a mean dominant frequency of $8,300 \mathrm{~Hz}$ (Thomsen et al., 2000).

Behavioral responses to boat (as opposed to ship) noise have been documented in toothed whales, including SRKWs. For example, bottlenose dolphins whistle (at 4,000-20,000 Hz) less when exposed to boat noise at 500-12,000 Hz (Buckstaff, 2004) and Indo-Pacific bottlenose dolphins lower their 5,000$10,000 \mathrm{~Hz}$ whistle frequencies when noise is increased by boats in a band from 5,000-18,000 Hz (Morisaka et al., 2005). For every $1 \mathrm{~dB}$ increase in broadband underwater noise $(1,000-40,000 \mathrm{~Hz})$ associated with nearby boats, SRKWs compensate by increasing the amplitude of their most common call by $1 \mathrm{~dB}$ (Holt et al., 2009).

While the frequencies used by toothed whales are well above the peak power frequencies of ships, multiple lines of evidence suggest that ship noise spectra extend or should be expected to extend to higher frequencies. Laboratory experiments with cavitation and previous studies of submarines, torpedoes, and ships indicate that ship noise may extend as high as $160,000 \mathrm{~Hz}$ at the source.

Experiments confirm that cavitation generates high frequency noise up to at least $100,000 \mathrm{~Hz}$ (Wenz, 1962). Cavitation noise from spinning rods and water jets has spectral power that rises through low frequencies at a rate of $40 \mathrm{~dB} / \mathrm{dec}$ de to a peak near $1,000 \mathrm{~Hz}$ and thereafter descends at $-20 \mathrm{~dB} / \mathrm{dec}$ ade (Mellen, 1954; Jorgensen, 1961). Noise from foil cavitation also has peak spectral power at 1,000 Hz, as well as a secondary peak at $31,000 \mathrm{~Hz}$ (Blake et al., 1977). In the vicinity of the higher peak, 1/3-octave levels increase about $10 \mathrm{~dB}$ upon cavitation inception (Blake et al., 1977).

World War II studies of ship noise, particularly measurements of thousands of transits of hundreds 
of ships of all types, identified propeller cavitation as the dominant source of noise radiated by ships, including at high frequencies (Dow et al., 1945). In reviewing these studies Ross (1976) and Urick (1983) noted that increases of $>40 \mathrm{~dB}$ in the $10,000-30,000 \mathrm{~Hz}$ band were diagnostic of cavitation inception on accelerating twin-screw submarines and Urick (1983) attributed a $1 \mathrm{~dB} / \mathrm{knot}(2 \mathrm{~dB}$ per m/s) rise in torpedo spectrum levels from 10,000-75,000 $\mathrm{Hz}$ to propeller cavitation.

More recently, cavitation has been implicated in ship noise measurements made at close range $(<1,000 \mathrm{~m})$ which show levels between $1,000-160,000 \mathrm{~Hz}$ that not only are significantly above background levels, but also rise with increased ship speed faster than at lower frequencies (Arveson and Vendittis, 2000; Kipple, 2002; Hermannsen et al., 2014). Even when portions of the high-frequency energy are excluded, broadband source levels of cavitating propellers are high. Erbe and Farmer (2000) reported median broadband $(100-20,000 \mathrm{~Hz})$ source levels for an icebreaker with a cavitating propeller of $197 \mathrm{~dB}$ re $1 \mu \mathrm{Pa} @ 1 \mathrm{~m}$.

In the open ocean or on the outer continental shelf far from shipping lanes high-frequency noise radiated by a ship will be absorbed within about $10 \mathrm{~km}$ (Erbe and Farmer, 2000), often before reaching a species of concern. In urban estuaries, however, marine mammals are exposed to noise from ships at ranges of 1-10 km routinely, and less than $100 \mathrm{~m}$ occasionally. For example, SRKWs frequently transit Haro Strait within 10 to $300 \mathrm{~m}$ of the shoreline at Lime Kiln Point where they are about $2 \mathrm{~km}$ from the center of the northbound (nearest) shipping lane (Figure 1). Since the absorption rate is only about $3 \mathrm{~dB} / \mathrm{km}$ at 20,000 Hz, compared to $30 \mathrm{~dB} / \mathrm{km}$ at 100,000 Hz (Francois and Garrison, 1982), ship noise near $20,000 \mathrm{~Hz}$ (where SRKWs are most sensitive) in such close quarters may retain the potential to mask echolocation clicks, as well as other high-frequency signals.

In an environment where SRKWs may already be food-stressed (Ayres et al., 2012) due to reduced populations of their primary prey - Chinook salmon (Hanson et al., 2010) - echolocation masking could have grave population-level consequences. The potential impacts of ship noise on foraging efficiency may be compounded by simultaneous masking of communication calls, some of which may help coordinate foraging or prey sharing (Ford and Ellis, 2006). One case study has suggested that ship noise may reduce foraging efficiency by 50\% in Curvier Beaked whales (Aguilar Soto et al., 2006).

Motivated by the possible impacts of ship noise on odontocetes and the scarcity of ship noise measurements made at close range over the full range of frequencies used by SRKWs, we endeavor to estimate source spectrum levels up to $40,000 \mathrm{~Hz}$ for a wide variety of ships from measurements made at a range of less than a few kilometers. Our primary objective is to characterize ship noise at higher frequencies, specifically those important to killer whales. A secondary objective is to compare our results with previous studies in order to understand consistencies and possible biases in field measurements of 


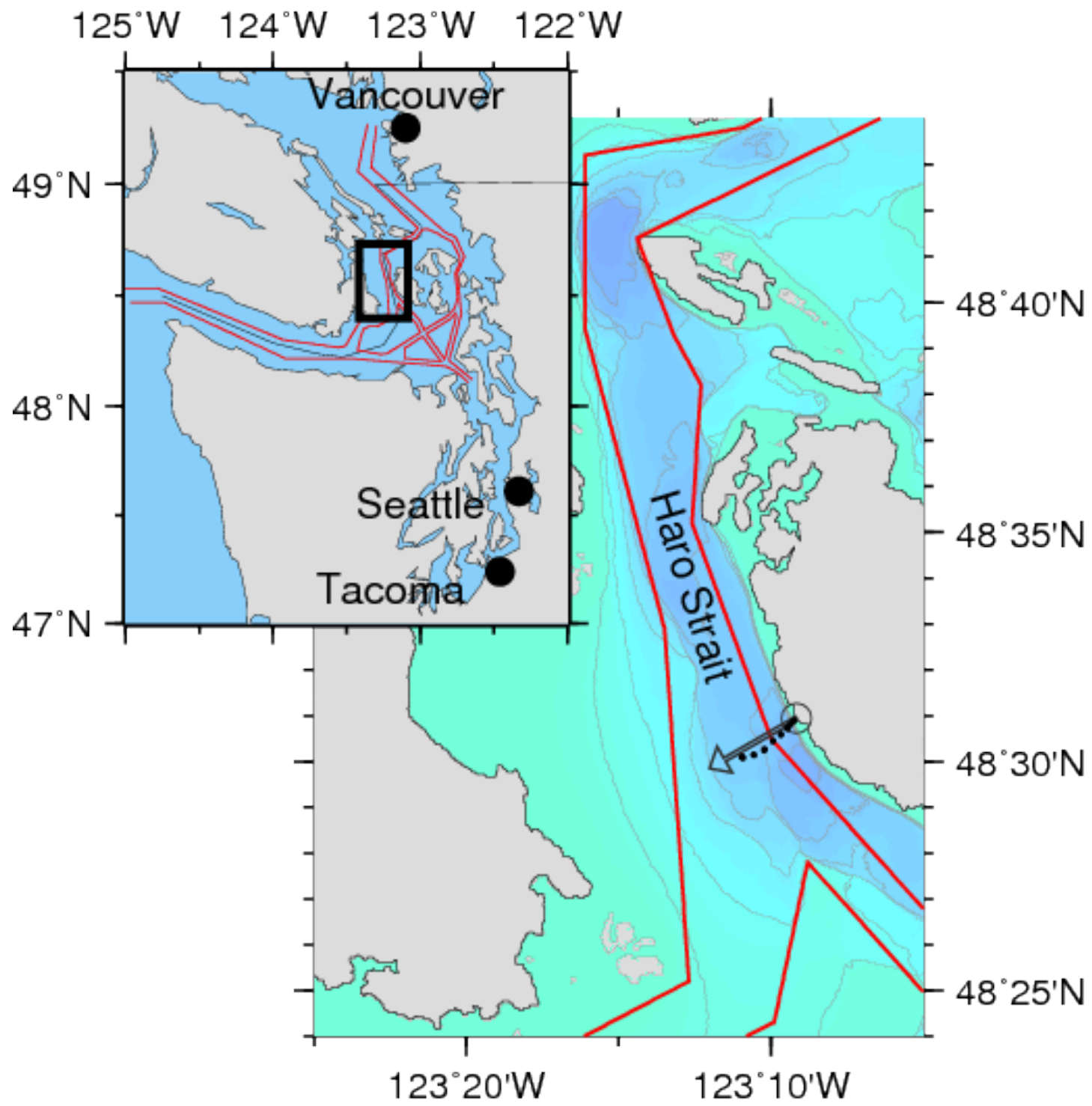

Figure 1. Inset regional map shows the study area (black rectangle) and shipping lanes (in red) leading to the major ports of the Salish Sea. The $240^{\circ}$ bearing (gray arrow) extends from the Lime Kiln hydrophone (gray circle) through the northbound shipping lane. Bathymetric contours $(50 \mathrm{~m})$ show that Haro Strait is a steep-sided 200-300 m-deep channel. Sound projection locations (black dots) are sites used for the transmission loss experiment.

\section{METHODS}

Our study site is an area of the inland waters of Washington State and British Columbia known as the Salish Sea. This urban estuary hosts the commercial shipping ports of Vancouver, Seattle, and Tacoma (see Figure 1).

Shipping traffic primarily associated with Vancouver - about 20 large ( $>65$ feet or $19.8 \mathrm{~m}$ ) vessels per day (Veirs and Veirs, 2006) - transits Haro Strait, the core of the summertime habitat of the 
SRKWs (Hauser et al., 2007). Each ship typically raises sound pressure levels ${ }^{1}$ near the shoreline about $20 \mathrm{~dB}$ re $1 \mu \mathrm{Pa}$ (RMS, 100-15,000 Hz) above background levels to about $115 \mathrm{~dB}$ for approximately 20 minutes/transit (Veirs and Veirs, 2006). We define ships as all vessels with overall length (LOA) greater than 65 feet $(19.8 \mathrm{~m})$; the remaining, shorter vessels (boats) are not characterized in this study.

We measured underwater noise radiated by these ships, collecting data continuously during 28 months between March 7, 2011, and October 10, 2013, except for occasional 1-2 day interruptions caused by power outages. About 3.5 months of data were excised due to systematic noise caused during equipment repairs made between July 22, 2011, and November 9, 2011. Consequently, we sampled every month of the year at least twice.

\section{Study site}

We deployed a calibrated hydrophone $50 \mathrm{~m}$ offshore of the lighthouse at Lime Kiln State Park in which The Whale Museum and Beam Reach maintain an acoustic observatory as part of the Salish Sea Hydrophone Network (orcasound.net). Midway along the west side of San Juan Island, Lime Kiln lighthouse sits on a point near the center of the summertime habitat of the SRKWs (Figure 1). While the killer whales sometimes swim directly over the hydrophone location, they more typically transit the site 100-300 m offshore where received levels of noise from the shipping lanes would be somewhat higher than those recorded in this study.

The hydrophone was secured to a PVC pipe projecting vertically from a cement-filled tire resulting in a position $1 \mathrm{~m}$ above the bottom at a depth of $8 \mathrm{~m}$ (below mean lower low water). A cable protected by irrigation pipe secured in the inter- and sub-tidal zones brought the signal to recording hardware within the lighthouse and also housed a saltwater ground wire that helped reduce system noise.

The local bathymetry on a transect perpendicular to the shoreline ( $240^{\circ}$ bearing) and running from the hydrophone to the northbound shipping lane descends to deep ( $>200 \mathrm{~m}$ ) water within $300 \mathrm{~m}$ of the shoreline. The nearshore region $(<150 \mathrm{~m}$ from shore) has a substrate of boulders and gravel covered with marine vegetation and descends at a slope of about $20^{\circ}$. Further from shore the bottom descends at a slope of about $45^{\circ}$.

Relative to the northbound shipping lane the hydrophone position is $1.3 \mathrm{~km}$ from the eastern edge, $2.25 \mathrm{~km}$ from the center of the lane, and about $3.7 \mathrm{~km}$ from the center of the traffic separation zone. A histogram of the range to all ships in our database shows peaks at 2.3 and $5.0 \mathrm{~km}$, corresponding with the middle of the north- and south-bound lanes, respectively.

\footnotetext{
${ }^{1}$ All decibels here are referred to $1 \mu \mathrm{Pa}$ and source levels to a distance of $1 \mathrm{~m}$. After their first usage, the units of broadband and spectrum level decibels are generally suppressed.
} 


\section{Data acquisition}

We made audio recordings of the signal from a Reson TC4032 hydrophone installed with a differential output (sensitivity of $-164 \pm 3 \mathrm{~dB}$ re $1 \mathrm{~V} / \mu \mathrm{Pa}$ from $5-125,000 \mathrm{~Hz}$ ) that was amplified and then digitized by a MOTU Traveller sampling at $192,000 \mathrm{~Hz}$ with 16 bits per sample. The maximum signal that could be recorded without clipping was $140 \mathrm{~dB}$.

A Windows XP computer analyzed and archived the recorded signal. We calibrated the recording system with the analog output of an Interoceans 902 (acoustic listening calibration system) while a ship was passing the lighthouse, thereby converting the samples to decibels (dB) referenced to $1 \mu \mathrm{Pa}$ (hereafter $\mathrm{dB}$ re $1 \mu \mathrm{Pa}$ ). This procedure was carried out occasionally to check and make minor changes in the Reson calibration constant during the 28 month study period.

A Python program analyzed the digitized hydrophone signal. The program continuously computed running 2-second mean square voltage levels. Each hour the program archived the 2-second recordings that yielded the minimum and maximum averages. We used the minimum files to determine background noise levels.

Generally, all commercial ships over 300 tons are required to use the Automatic Identification System (AIS) to broadcast navigational data via VHF radio. The AIS carriage requirements of the U.S. Coast Guard (33 CFR 164.46) and Canada within a vessel traffic service area like Haro Strait mean that some fishing and passenger vessels may be underrepresented in our data set. Each AIS-equipped ship transmits at least its identification number, location, course, and speed a few times each minute. The typical range over which these transmissions are detected is $45 \mathrm{~km}$.

The Python program scanned the binary output of an AIS receiver (Comar Systems AIS-2-USB) located in the lighthouse. For each transmission received, the location of the ship was used to calculate its range $(R)$ from the hydrophone. When $R$ was less than 4 nautical miles $(7.4 \mathrm{~km})$, the program recorded the broadband received level every 0.5 nautical mile $(926 \mathrm{~m})$ as the ship approached and departed. When the ship crossed a line perpendicular to shore (at an azimuth angle of $240^{\circ}$ true, see Figure 1), the Python program stored a 30-second WAV file, the date and time, and the decoded ship metadata (ship ID number, range, speed over the ground $[S O G]$, and course over the ground). Given the orientation of the northbound shipping lane, this procedure made it likely that we recorded the starboard beam aspect noise levels of each isolated ship near the closest point of approach. Finally, the program calculated the calibrated broadband received level using the Reson calibration constant and the RMS amplitude of the 30-second file.

To maximize the detection of any high-frequency signal generated by passing ships, and to reduce the spatial extent of our transmission loss experiment, we elected to compute source levels for only the 
closer, northbound portion of the traffic in Haro Strait. Southbound traffic was recorded, counted, and archived, but is not included in this analysis. For the northbound traffic presented herein, the mean and standard deviation of $R$ is $2.30 \pm 0.39 \mathrm{~km}$, and the minimum and maximum $R$ are $0.95 \mathrm{~km}$ and $3.65 \mathrm{~km}$, respectively.

\section{Data analysis}

\section{Isolation and identification}

Archived WAV files and associated metadata were analyzed with a $\mathrm{C}++$ program developed in the platform-independent Qt environment (qt-project.org). To measure the noise radiated by an individual ship, rather than multiple ships, the program used the AIS data to detect acoustically-isolated ships. A ship was deemed isolated if the previous and subsequent ships were at least 6 nautical miles $(11.1 \mathrm{~km})$ away from the hydrophone when the WAV file was recorded. It is only at closer range that human listeners can detect ship noise above ambient levels.

For each isolated ship, the program used the ship's identification (Maritime Mobile Service Identity, or MMSI) number to look up details about the ship from online web sites such as the Marine Traffic network (www.marinetraffic.com). These metadata, saved in a MySQL database, include (when available): MMSI, ship name, ship type, year built, length, breadth, dead weight, maximum and mean speed, flag, call sign, IMO, draft, maximum draft, and photographs.

We simplified 41 ship type categories returned from online queries into 12 general ship classes: bulk carrier (includes ore carriers); container; tug (includes multi-purpose offshore, pusher tug, and tender); cargo (includes other cargo, heavy lift, wood chip carrier); vehicle carrier (includes all roll-on roll-offs); tanker (includes crude oil, oil product, oil/chemical, chemical, and product tankers); military (includes Coast Guard, search and rescue); fishing (includes fish carrier, factory, fishing, fishing vessel, and trawler); passenger (includes cruise ships and ferries); miscellaneous (includes cable layer, reserved, unspecified, and well-stimulation); pleasure craft (includes sailing vessels, motor yacht, and yachts); and research.

\section{Received levels}

From each isolated ship's WAV file the RMS power spectral density (PSD) was calculated using a Fast Fourier Transform averaged over the 30-second duration of the file (Nyquist frequency of 96,000 Hz; $16,384\left(2^{14}\right)$ sample overlapping Bartlett window). The bandwidth of each of the 8,192 frequency bins was $11.5 \mathrm{~Hz}$. These RMS PSD (per Hz) values were calibrated by requiring that the integral of the PSD equal the calibrated broadband level associated with each WAV file. The resulting power spectral densities we call the total received spectrum levels.

The total received spectrum level is a composite of the power that originated from the ship and the power associated with the background noise at the time of the ship passage. To enable estimation of the 
background level at the time of ship passage we continuously observed 2-second sound samples, saving the lowest power 2-second sample every hour.

The subtraction of the estimated background received level $\left(R L_{B}\right)$ from the total received spectrum level $\left(R L_{T}\right)$ to determine the received spectrum level associated with the ship $\left(R L_{S}\right)$ is based on the fact that when two or more waves pass at once, the pressure on the hydrophone $(P)$ is the sum of the instantaneous pressure from each wave. The power that we calculate is proportional to the square of the pressure on the hydrophone and is represented in decibels. These relationships apply both for the power at individual frequencies (PSD) and the total power $\left(P w r_{T}\right)$ integrated over all frequencies.

Following the nomenclature of Erbe (2011),

$$
P w r_{T}(t)=k\left(P_{S}(t)+P_{B}(t)\right)^{2}
$$

where $k$ is a constant dependent on the construction of the hydrophone and $t$ is time. Averaging over the 30 seconds of each WAV file, we assume that the pressure due to the ship at each moment in time is not correlated with the pressure due to other (background) noise sources. Thus, the power received from the ship is the average total power minus the average background power:

$$
\left\langle P w r_{S}\right\rangle=\left\langle P w r_{T}\right\rangle-\left\langle P w r_{B}\right\rangle
$$

We estimate $P w r_{B}$ for each passing ship as the average of the power in two samples - the quietest 2-second sample from the hour before the ship is recorded, and quietest from the hour after the ship passage.

On occasion during daylight hours, ship recordings contain noise from vessels unequipped with AIS (usually recreational motorboats and occasionally larger vessels operating without AIS). This contamination is limited to the 50,75 , and $95 \%$ quantiles above $20,000 \mathrm{~Hz}$, has peak spectrum levels near $50,000 \mathrm{~Hz}-$ a frequency commonly used for depth sounders - and is rare, but we have nevertheless reduced it via a 2-step statistical process.

Since it is very rare to have motorboat noise overlapping with ship passage at night, we first determined the 95\% quantile of each received spectrum level across all vessels recorded at night (hour of day greater than 19:00 or less than 07:00) and used it as a threshold above which contamination by boat noise may have occurred. Then we re-processed all ship transits, removing any data points for which the threshold was exceeded. Any recording in which at least 100 of the 8,192 spectral received levels were above threshold was omitted from further statistical analysis. 
Through this robust statistics process, about $15 \%$ of transits were omitted, resulting in no difference between the ship population quantiles for ships that pass during the day versus the night. A sensitivity analysis shows that the process did not affect the 5\% to $75 \%$ quantiles and that the $95 \%$ quantile was reduced by less than $2 \mathrm{~dB}$ - and only above about $20,000 \mathrm{~Hz}$. The high frequency peaks seen in the $95 \%$ quantile in Figure 3 become sharper as the threshold is increased or the total number of vessels analyzed is decreased.

Finally, we report received levels $(R L)$ in decibels relative to a reference pressure of $1 \mu$ Pascal and estimate ship received levels as:

$$
R L_{S}=10 \log _{10}\left(10^{R L_{T} / 10}-10^{R L_{B} / 10}\right)
$$

Often $R L_{T}$ is much higher than $R L_{B}$ at all frequencies. In such cases, subtraction of the background has little effect on $R L_{S}$. But for many ships $R L_{T}$ is close to $R L_{B}$, at least at some frequencies. Therefore, we subtract the estimated background from the $R L_{T}$ at all frequencies for every isolated ship, yielding the received spectrum level of ship noise, $R L_{S}$.

We cannot determine $R L_{S}$ if the associated $R L_{T}$ is not greater than $R L_{B}$. Hence we require that $R L_{T}$ at any given frequency must exceed a threshold of three times the background spectrum level at that frequency. We choose this factor $(4.8 \mathrm{~dB})$ by examining the statistics of typical ship and background recordings to assure that noise is unlikely to be taken as signal. We refrain from reporting ship source spectra above $40,000 \mathrm{~Hz}$ because the sample size in bands above this frequency falls below about $10 \%$ of the mean sample size in lower frequency bands. Furthermore, to calculate broadband source levels with or without absorption we integrate the spectrum levels only up to this $40,000 \mathrm{~Hz}$ upper limit.

Prior to the background subtraction, our data commonly contained narrow-band noise peaks near 25, 38, 43, 50 and $69 \mathrm{kHz}$ in many of the background and total received spectrum level quantiles (Figure 3). Unknown sources of transient systematic noise (most commonly near $77 \mathrm{kHz}$ ), typically lasted only a few days. Because these noise sources are narrow or brief, they contain little power. Also, since they occur in both the received level and background data, they tend to be removed through background subtraction, and therefore do not significantly contaminate the estimated source levels (Figure 4). One exception is the peak near $25 \mathrm{kHz}$ - likely associated with the Jim Creek Naval Radio Station (transmitting at $24.8 \mathrm{kHz}$ ) - which persists in many source level spectra, probably indicating that the submarine communications are intermittent, at times occurring during a ship passage but not during the corresponding background measurements. 


\section{Transmission loss experiment}

To estimate the source spectrum level of isolated ships from $R L_{S}$ we measured the transmission loss along the $240^{\circ}$ true bearing line from the near-shore hydrophone at Lime Kiln into the northbound shipping lane (Figure 1). The transmission loss is a combination of geometric spreading and frequency-dependent absorption. While Haro Strait has less distinct winter and summer sound speed profiles than other parts of the Salish Sea due to vertical mixing by tidal flow over bounding sills, to average out any seasonal effects we conducted our transmission loss experiment in the spring.

We determined the geometric spreading via a field experiment conducted in March, 2014, from a $10 \mathrm{~m}$ catamaran. We projected a sequence of 2-second tones (Table 1) using a Lubell 9816 underwater speaker lowered in a bifilar harness from the bows and attached to a power amplifier and a digital sound player. During each tone sequence, we noted the location of the projector on the sailboat's GPS and measured the projected sound level with the Interoceans 402 hydrophone, having positioned its calibrated hydrophone near the stern, about $10 \mathrm{~m}$ from the projector. We oriented the projection system toward the lighthouse as we played each sequence at the following distances from the projector to the Lime Kiln hydrophone: 290; 1,$035 ; 1,446$; and $2,893 \mathrm{~m}$.

This study focuses on determining the source levels of ships that are northbound at Lime Kiln lighthouse. By limiting our analysis to northbound vessels we reduce the difficulty of determining accurate transmission loss by limiting the variation in range of the targets. Furthermore, our underwater speaker used to measure transmission loss did not have sufficient power especially at high frequencies (near 20,000 Hz) to provide detectable signals at ranges much larger than the 2,893 m range that brackets the more distant edge of the north bound traffic lane.

We analyzed the spreading of the test tones by measuring the calibrated RMS level received at the Lime Kiln hydrophone for each tone at each distance. The received signal was determined by subtracting the calibrated background level from the received level of the corresponding tone (Equation 3). To determine the geometric spreading contribution to transmission loss, we added to the received signal levels the amount of absorption expected for each frequency and range (straight line path, $R$ ). Following Francois and Garrison (1982) we used $R$ to calculate the absorption loss at each frequency. For our highest test tone frequencies and range, accounting for absorption added from $2 \mathrm{~dB}$ (at 10,000 $\mathrm{Hz}$ ) to $8.6 \mathrm{~dB}$ (at $20,000 \mathrm{~Hz}$ ) back into the received signal levels.

We used linear regression to model the absorption-corrected received signal levels as a function of the base 10 logarithm of the range from receiver to source in meters separately for each of our test tones. The slopes and goodness of fit are shown in Table 1. Since these slopes are not correlated with the frequency (correlation coefficient of 0.003), we average them and use the resulting near-spherical 
geometric spreading coefficient (transmission loss coefficient, $T L$ ) of $-18.6 \pm 0.4 \mathrm{~dB} /$ decade in $\log _{10}(R)$ to represent geometric spreading out to a distance of about $3 \mathrm{~km}$. Also, as these slopes vary little over a factor of 30 in frequency we assume that we can use this mean slope to extrapolate down from $630 \mathrm{~Hz}$ to our $20 \mathrm{~Hz}$ lower frequency cutoff and up from $20,000 \mathrm{~Hz}$ to our $96,000 \mathrm{~Hz}$ upper frequency Nyquist cutoff.

\begin{tabular}{|c|c|c|}
\hline $\begin{array}{l}\text { Frequency } \\
(\mathrm{Hz})\end{array}$ & $\begin{array}{l}T L \\
\text { (dB/decade) }\end{array}$ & $\begin{array}{l}\text { coefficient of } \\
\text { determination }\end{array}$ \\
\hline 630 & -18.85 & 0.926 \\
\hline 1,260 & -18.08 & 0.991 \\
\hline 2,510 & -18.99 & 0.986 \\
\hline 5,000 & -18.24 & 0.964 \\
\hline 10,000 & -18.37 & 0.974 \\
\hline 15,000 & -19.09 & 0.987 \\
\hline 20,100 & -18.67 & 0.971 \\
\hline
\end{tabular}

Table 1. Results of the transmission loss experiment. For each projected frequency, the geometric spreading rate $(T L)$ is near-spherical, with an average slope of $-18.6 \pm 0.4 \mathrm{~dB} / \mathrm{decade}$.

\section{Source levels}

We calculate source spectrum levels of ship noise without absorption $(S L)$ in equation (4) and then with absorption $\left(S L_{a}\right)$ in equation (5), determining $\alpha$ from Francois and Garrison (1982).

$$
S L=R L_{S}+18.6 \log _{10}(R)
$$

$$
S L_{a}=R L_{S}+18.6 \log _{10}(R)+\alpha(f) R
$$

$$
\text { We integrate the source spectrum levels from } 11.5 \mathrm{~Hz} \text { up to } 40,000 \mathrm{~Hz} \text { to compute broadband source }
$$
levels ( $S L$ ) (Table 2). We also integrate the source spectrum levels over both 1/3-octave and 1/12-octave bands with band centers determined by $f(i)=f_{o} 2^{\frac{i}{N}}$ where $i$ is an integer and $N$ is the number of partitions of each octave. This is both consistent with ISO center frequencies (ISO 266) and allows comparison with the proposed annual mean noise thresholds at 63 and 125 Hz Tasker et al. (2010); Merchant et al. (2014). Finally, when plotting quantiles of levels we exclude the lowest frequency bin $(11.5 \mathrm{~Hz})$ because for some classes an insufficient number of ships passed the $4.8 \mathrm{~dB}$ re $1 \mu \mathrm{Pa}$ signal-noise threshold to estimate the $5 \%$ and $95 \%$ quantiles.

To facilitate comparison with past studies we generally present ship source spectrum levels as $S L$. However, due to the presence of high-frequency ship noise in our recordings and its potential impact on 
marine life exposed at close range, we also present absorption-corrected spectral power levels $\left(S L_{a}\right)$ for the whole ship population.

\section{RESULTS AND DISCUSSION}

\section{Ship traffic patterns}

Combining all ship classes over the entire study, our data set describes 1,582 unique vessels that made a total of 2,809 isolated, northbound transits of the shipping lanes in Haro Strait (Table 2). The 2,809 isolated transits sample $17.1 \%$ of the total transits through Haro Strait (16,357, northbound and southbound) logged by our AIS system during the study period. Of 7,671 total northbound transits, $36 \%$ were sampled, suggesting that about 2/3 of the traffic in Haro Strait is not isolated. Dividing the total transits by the 850 day study period shows that the average daily ship traffic is 19.5 ships/day. This amount of traffic is comparable to previous estimates for Haro Strait: about 20 ships/day (Veirs and Veirs, 2006) and about 1 ship/hour (Erbe et al., 2012).

About $1 / 3$ of the isolated transits are bulk carriers and about $1 / 5$ are container ships. The next 4 most prevalent ship classes - tugs, cargo ships, vehicle carriers, and tankers - constitute another $1 / 3$ of the isolated transits. Of the remaining less-prevalent ship classes, we sample military ships 113 times (19 unique vessels), and other ship classes 18 to 65 times.

Together, bulk carriers and container ships comprise more than half $(53 \%)$ of the isolated shipping traffic in Haro Strait. About 3/4 of isolated bulk carrier transits are unique vessels, in contrast to container ships which are unique only about $40 \%$ of the time. This may indicate that the global bulk carrier fleet is larger than the container fleet, or that shipping economics or logistics limit the diversity of container ships transiting Haro Strait. For example, container ships may ply routes that are more fixed, and therefore repeat transits through Haro Strait more frequently than bulk carriers.

Those ship classes that have many isolated transits by a small number of unique ships offer us opportunities to study variability of noise from individual ships. Military vessels, a category with 19 unique ships sampled on 113 isolated transits, have about 7 isolated transits per unique ship, while tugs and research vessels have about 4 and container ships have about 3 .

\section{Broadband levels}

\section{Received levels}

Broadband population mean received levels $\left(R L_{S}\right.$, Table 2$)$ vary between ship classes from a low of $97 \mathrm{~dB}$ (pleasure craft) to a high of $116 \mathrm{~dB}$ (container ships). Combining all classes, $R L_{S}$ is $110 \pm 7 \mathrm{~dB}$ which is $19 \mathrm{~dB}$ re $1 \mu \mathrm{Pa}$ above the mean background level $\left(R L_{B}\right)$ of $91 \pm 4 \mathrm{~dB}$. These levels are comparable to anthropogenic and background received levels noted in previous studies at similar distances to shipping 


\begin{tabular}{lrrrllrr} 
& $\begin{array}{c}\text { Isolated } \\
\text { transits }\end{array}$ & $\begin{array}{c}\% \text { of } \\
\text { total }\end{array}$ & $\begin{array}{c}\text { Unique } \\
\text { ships }\end{array}$ & $R L_{S}$ & \multicolumn{1}{l}{$S L$} & $S O G$ & $S O G$ \\
Ship class & & & & $\mathrm{dB}$ & $\mathrm{dB}$ & $\mathrm{m} / \mathrm{s}$ & knots \\
All classes combined & 2,809 & & 1,582 & $110 \pm 7$ & $173 \pm 7$ & $7.3 \pm 2.0$ & $14.1 \pm 3.9$ \\
Bulk carrier & 965 & 34.3 & 734 & $111 \pm 6$ & $173 \pm 5$ & $7.0 \pm 0.8$ & $13.7 \pm 1.5$ \\
Container & 529 & 18.8 & 207 & $116 \pm 4$ & $178 \pm 4$ & $9.9 \pm 1.0$ & $19.2 \pm 1.9$ \\
Tug & 337 & 12.0 & 85 & $108 \pm 5$ & $170 \pm 5$ & $4.2 \pm 1.2$ & $8.2 \pm 2.3$ \\
Cargo & 307 & 10.9 & 206 & $113 \pm 5$ & $175 \pm 5$ & $7.4 \pm 1.2$ & $14.4 \pm 2.3$ \\
Vehicle carrier & 187 & 6.6 & 111 & $113 \pm 3$ & $176 \pm 3$ & $8.7 \pm 1.0$ & $16.9 \pm 1.8$ \\
Tanker & 148 & 5.3 & 101 & $111 \pm 5$ & $174 \pm 4$ & $7.1 \pm 0.7$ & $13.8 \pm 1.4$ \\
Military & 113 & 4.0 & 19 & $99 \pm 10$ & $161 \pm 10$ & $5.7 \pm 1.6$ & $11.1 \pm 3.1$ \\
Fishing & 65 & 2.3 & 28 & $102 \pm 9$ & $164 \pm 9$ & $4.7 \pm 1.1$ & $9.1 \pm 2.2$ \\
Passenger & 49 & 1.7 & 31 & $104 \pm 8$ & $166 \pm 8$ & $7.4 \pm 2.3$ & $14.4 \pm 4.5$ \\
Miscellaneous & 41 & 1.4 & 21 & $101 \pm 9$ & $163 \pm 9$ & $5.8 \pm 3.0$ & $11.2 \pm 5.8$ \\
Pleasure craft & 41 & 1.5 & 35 & $97 \pm 10$ & $159 \pm 9$ & $6.4 \pm 2.5$ & $12.4 \pm 4.9$ \\
Research & 14 & 0.5 & 4 & $104 \pm 6$ & $167 \pm 5$ & $5.7 \pm 0.9$ & $11.1 \pm 1.8$
\end{tabular}

Table 2. Ship population statistics and mean broadband sound pressure levels $(20-40,000 \mathrm{~Hz})$. Though abbreviated in the table as $\mathrm{dB}$, the units of the received signal levels $\left(R L_{S}\right)$ are $\mathrm{dB}$ re $1 \mu \mathrm{Pa}$ and source levels have units of dB re $1 \mu \mathrm{Pa} @ 1 \mathrm{~m}$. Variability is reported as a standard deviation of the mean, and speed over ground ( $\mathrm{SOG}$ ) is provided in $\mathrm{m} / \mathrm{s}$ and knots.

lanes and over similar frequency ranges (Veirs and Veirs, 2006; McKenna et al., 2012). While our $R L_{S}$ from ships 0.95-3.65 km away is 10-22 dB lower than the 121-133 dB reported by Bassett et al. (2012), only about $2 \mathrm{~dB}$ of this difference can be explained by the shorter distances to their ships $(0.58-2.82 \mathrm{~km})$.

\section{Source levels (SL)}

The mean broadband source level ( $S L$, Table 2) for all ship classes combined is $173 \pm 7 \mathrm{~dB}$ re $1 \mu \mathrm{Pa} @ 1 \mathrm{~m}$. Comparing between ship classes, container ships have the highest $S L$ at $178 \mathrm{~dB}$. Other classes with $S L \geq 173 \mathrm{~dB}$ include vehicle carriers, cargo ships, tankers, and bulk carriers. Tugs, research, and passenger vessels (primarily cruise ships, as there are no nearby ferry routes) have $S L$ of $166-170 \mathrm{~dB}$, while the remaining vessel classes have $S L$ from 159-164 dB. This range of $S L$ across classes (159-178 dB) overlaps the 170-180 dB range specified for small ships (lengths 55-85 m) by Richardson et al. (1995). When frequency dependent absorption is included, mean broadband source levels increase by $0.5-1 \mathrm{~dB}$ (we have limited the upper frequency to $40,000 \mathrm{~Hz}$ ).

Our range of mean values is similar to recent estimates of broadband source levels for similar-sized modern vessels, but for some classes other estimates are 1-11 dB higher than our estimates. Figure 2 depicts broadband $S L$ statistics for each class we studied and juxtaposes the results from other studies of modern ships for comparable classes. Some of these studies are discussed below, partially to assess our results and partially to consider some of the common ways in which methods may differ between studies of ship noise: sample sizes, bandwidths, averaging times, calibration procedures, background subtractions, absorption or other frequency-dependent corrections, geometric spreading rates, and ship characterization (e.g. classification, criteria for isolation, speed, and range). 
Compared with mean broadband source levels $(20-30,000 \mathrm{~Hz}, T L$ of -15 , absorption assumed negligible) computed by Bassett et al. (2012) our means are 0-6 dB lower, depending on the class. The comparatively low values of our means cannot be explained by distinct methodology; their study used a narrower broadband bandwidth and a lower (modeled) transmission loss. The most likely explanation for the differences in most classes is a difference in distinct ship design and/or operating characteristics between Puget Sound and Haro Strait populations. There is some evidence that ships measured by Bassett et al. (2012) may have higher speeds than in our study. Of the 24 select ships for which Bassett et al. (2012) provide speed data, 38\% have SOG greater than 1 standard deviation above our mean values for the corresponding class. The average elevation of $S O G$ for those ships is $+2.0 \mathrm{~m} / \mathrm{s}(+3.8$ knots).

Compared with broadband source levels $(20-1000 \mathrm{~Hz}, T L$ of -20$)$ listed for 29 individual ships by McKenna et al. (2012) the mean values for equivalent classes in Table are 1-13 dB lower. These differences are also depicted in Figure 2. Accounting for the difference in $T L$ ( $1.4 \mathrm{~dB} / \mathrm{decade}$ of range) between the studies would raise our $S L$ values an average of $4.7 \mathrm{~dB}$, thereby causing our inter-quartile range to overlap with or encompass the ranges of McKenna et al. (2012) for all comparable classes except bulk carriers. As with the Bassett et al. (2012) study, adjusting for differences in broadband bandwidth would raise their individual ship source levels even higher above our means, so cannot help explain the differences. Examining the $S O G$ differences by class offers less of an explanation in this case; of the 29 ships, only 3 (about 10\%) have speeds that exceed our mean SOG in the associated class, and only by an average of $1 \mathrm{~m} / \mathrm{s}$ ( 2 knots).

A study of 593 container ship transits by McKenna et al. (2013) yielded a mean source level (20$1000 \mathrm{~Hz}, T L$ of -20 ) for the population of $185 \mathrm{~dB}, 7 \mathrm{~dB}$ higher than our mean of $178 \mathrm{~dB}$ for 529 container ship transits. In the supplementary material McKenna et al. (2013) provide a mean speed of $10.5 \pm 1.4 \mathrm{~m} / \mathrm{s}$ - roughly $0.5 \mathrm{~m} / \mathrm{s}$ above our container ship mean speed of $9.9 \mathrm{~m} / \mathrm{s}$ - and an mean range of 3,246 $\pm 291 \mathrm{~m}$ (about $1 \mathrm{~km}$ larger than our mean range). The speed difference could only account for about $0.5 \mathrm{~dB}$ of the source level discrepancy between the studies, based on the $+2.2 \mathrm{~dB}$ per $\mathrm{m} / \mathrm{s}(+1.1 \mathrm{~dB} / \mathrm{knot})$ relationship between broadband source level and speed portrayed for a single ship in McKenna et al. (2013).

Compared with broadband source levels $(45-7,070 \mathrm{~Hz})$ of individual vessels measured by Malme et al. $(1982,1989)$ and tabulated by Richardson et al. (1995) our means for respective classes are $1 \mathrm{~dB}$ lower than a tug $(171 \mathrm{~dB}$ at $5.0 \mathrm{~m} / \mathrm{s}(9.7 \mathrm{knots})), 6 \mathrm{~dB}$ lower than a cargo ship $(181 \mathrm{~dB})$, and $12 \mathrm{~dB}$ lower than a large tanker $(186 \mathrm{~dB})$. These differences might be due to more modern ships decreasing their speed (at least while in coastal waters) or increasing their propulsion efficiency.

Kipple (2002) measured 6 cruise ships at a range of 500 yards and reported broadband source levels (10-40,000 Hz, TL of -20 , absorption ignored) of $175-185 \mathrm{~dB}$ re $1 \mu \mathrm{Pa} @ 1$ yard at 10 knots $(5 \mathrm{~m} / \mathrm{s})$ and 
178-195 dB re $1 \mu \mathrm{Pa} @ 1$ yard at 14-19 knots (7-10 m/s). In comparison, our population of passenger ships (including cruise ships) has a mean $S L$ of $166 \pm 8 \mathrm{~dB}$ re $1 \mu \mathrm{Pa} @ 1 \mathrm{~m}$ and a mean speed of $14.4 \pm 4.5$ knots. Thus, while the speeds tested by Kipple (2002) bracket our mean speed, our mean $S L$ is 9-29 dB lower than their range of source levels. One possible explanation for this difference is an unspecified upward correction of received levels below $300 \mathrm{~Hz}$ that Kipple (2002) made to account for multipath propagation effects. This is substantiated by Malme et al. (1989) who state that passenger vessels in Southeast Alaska have $S L$ from $170-180 \mathrm{~dB}$, a range that falls between our mean and maximum $S L$ for passenger vessels and mostly below the ranges given by Kipple (2002).

Finally, Arveson and Vendittis (2000) measured a bulk carrier at 8-16 knots (4-8 m/s) and found broadband source levels $(3-40,000 \mathrm{~Hz}, T L$ of -20$)$ of $178-192 \mathrm{~dB}$. The source levels they calculated for speeds of 12 knots $(6 \mathrm{~m} / \mathrm{s})$ and 14 knots $(7 \mathrm{~m} / \mathrm{s}), 184 \mathrm{~dB}$ and $190 \mathrm{~dB}$, respectively, are most comparable to our bulk carrier population with $S O G$ of $7.0 \pm 0.7 \mathrm{~m} / \mathrm{s}$. Without correction for the different transmission loss assumptions, our bulk carrier $S L$ of $173 \pm 5 \mathrm{~dB}$ is $11-17 \mathrm{~dB}$ below their levels.

While this pattern could be interpreted as an underestimation of $S L$ by our methods, we believe our population statistics represent an accurate estimate of source levels for modern ships operating in coastal waterways. In almost all of the cases that we have discussed, the maximum discrepancy is less than 1.5 times the inter-quartile distance ( $25 \%$ vs $75 \%$ quantiles) for the comparable ship class (see Figure 2). Exceptions are some of the louder container ships in McKenna et al. (2013) and vehicle carriers in McKenna et al. (2012), the large tanker mentioned in Richardson et al. (1995), the higher-speed cruise ships of Kipple (2002), and the bulk carrier of Arveson and Vendittis (2000) when its speed was greater than 8 knots $(4 \mathrm{~m} / \mathrm{s})$.

Even these exceptional upper values from the literature are almost completely contained within the distribution of our broadband $S L$ population. Our maximum $S L$ for a bulk carrier $(191 \mathrm{~dB})$ is $3.6 \mathrm{~dB}$ higher than the loudest bulk carrier tabulated in McKenna et al. (2012) and above the bulk carrier source levels obtained by Arveson and Vendittis (2000) at all speeds except 16 knots, or $8.2 \mathrm{~m} / \mathrm{s}$ (192 dB). The loudest bulk carrier tabulated in Bassett et al. (2012) with source level of $182 \mathrm{~dB}$ is equal to the $95 \%$ quantile of $S L$ within our bulk carrier class. The loudest ship tabulated by Richardson et al. (1995), a tanker with $S L$ of $186 \mathrm{~dB}$ ) is only $0.8 \mathrm{~dB}$ above our loudest tanker. One explanation for this outlier is that the ship was a supertanker driven by a steam-turbine - and therefore may represent the "upper range of large merchant vessels" (Malme et al., 1989). Finally, our passenger vessel population has a 95\% quantile of $177 \mathrm{~dB}$ and a maximum of $183 \mathrm{~dB}$, a range that encompasses most of the slow ships and the lower portion of the faster ships assessed by Kipple (2002).

Across all classes, the maximum broadband $S L$ for an individual ship was $195 \mathrm{~dB}$ for a container 
ship, 7 dB above the highest overall values reported by McKenna et al. (2012) and Bassett et al. (2012) both for container ships, as well. Our maximum is consistent with the study of 593 container ships by McKenna et al. (2013) in which the maximum source level was also $195 \mathrm{~dB}$. Our second- and third-highest maxima within a class were from a bulk carrier (191 dB) and a cargo ship (186 dB). All other classes had maximum $S L \leq 185 \mathrm{dBm}$. The lowest maximum $S L$ within a class was $176 \mathrm{~dB}$ for pleasure craft.

The range of minimum broadband $S L$ across all classes in our study was from $130 \mathrm{~dB}$ for a cargo ship to $167 \mathrm{~dB}$ for a vehicle carrier. In comparison McKenna et al. (2012) reported a minimum $S L$ across all classes of $177 \mathrm{~dB}$ for a chemical tanker while the minimum $S L$ for a container ship in McKenna et al. (2013) was $176 \mathrm{~dB}$. In contrast with the exact agreement of the maxima between our container ship population and the data set of McKenna et al. (2013), this discrepancy of at least 9-10 dB in $S L$ minima suggests that methodological differences between the studies may exert greater bias when ship signal levels are near background noise levels.

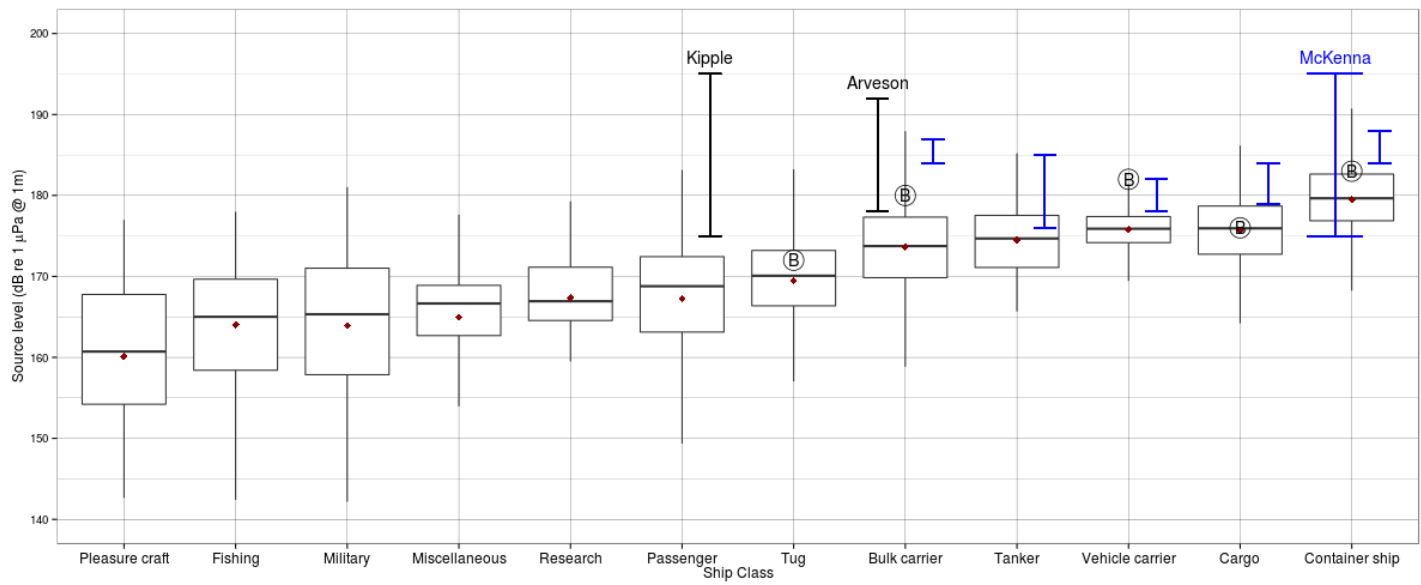

Figure 2. Broadband source level (SL) statistics for each ship class juxtaposed with results from recent studies of comparable classes. Bold horizontal lines are medians; gray box hinges are $25 \%$ and $75 \%$ quantiles; gray whiskers extend to the value that is most distant from the hinge but within 1.5 times the inter-quartile range (distance between the $25 \%$ and $75 \%$ quantiles); red dots are mean values from Table 2. Each encircled letter B represents a mean from Bassett et al. (2012); blue vertical bars represent means from McKenna et al. (2012) with the container ship estimate of McKenna et al. (2013) labeled McKenna; black vertical bars represent estimates from Kipple (2002) and Arveson and Vendittis (2000).

\section{Ship speed}

Averaged across all vessels, the $S O G$ of isolated ships northbound in Haro Strait is $7.3 \pm 2.0 \mathrm{~m} / \mathrm{s}$ (14.4 \pm 3.9 knots). This is higher than the mean of 10-12 knots (5.1-6.2 $\mathrm{m} / \mathrm{s}$ ) observed during WWII, but possibly lower than the post-war (mid-1970s) mean of about 15 knots (7.7 m/s) (Ross, 1976).

In our study, the fastest classes are container ships (mean $S O G$ of $9.9 \mathrm{~m} / \mathrm{s}$ ) and vehicle carriers $(8.7 \mathrm{~m} / \mathrm{s})$, while the slowest vessels are fishing boats $(4.7 \mathrm{~m} / \mathrm{s})$ and tugs $(4.2 \mathrm{~m} / \mathrm{s})$. For tankers, our $S O G$ of $7.1 \pm 0.7 \mathrm{~m} / \mathrm{s}$ is slightly below the 7.2-8.2 m/s (14-16 knot) range reported by (Ross, 1976) for both "T2 
tankers" in WWII and supertankers built after about 1960.

Overall, our data set samples a small range of ship speeds within any given class. Because Haro Strait is relatively long and straight, most vessels transit it without changing speed. Whether north- or south-bound, they have consistent $S O G$ means and standard deviations. This low variability in speed limits our ability to search for relationships between noise and speed, but may help us discern in future work the influence of other variables - like propeller type, draft (loading), or maintenance levels - building on insights from McKenna et al. (2013).

\section{Relationship between speed and broadband source level}

Upon linear regression of $S L$ versus $S O G$ for all data, we find a slope of $+1.8 \mathrm{~dB}$ per m/s $(+0.93 \mathrm{~dB} / \mathrm{knot})$. The coefficient of determination $\left(\mathrm{R}^{2}\right)$ for this fit explains only $27 \%$ of the variance in the data (assuming normal distribution). Furthermore, most of the variation in SL is likely driven by ship class (which was not controlled for in the regression), with little change in speed within ship class. Slopes vary from +0.2 to $+3.4 \mathrm{~dB}$ per $\mathrm{m} / \mathrm{s}$ between ship classes. Examination of repeated transits of individual ships shows that the variation in slope is high between individual ships within a class and the percent of variance explained is low. While slopes are positive for most individual ships, some are zero or negative. These variations indicate that the overall population slope should not necessarily be applied to all ship classes or individual ships, echoing the recommendations of McKenna et al. (2012).

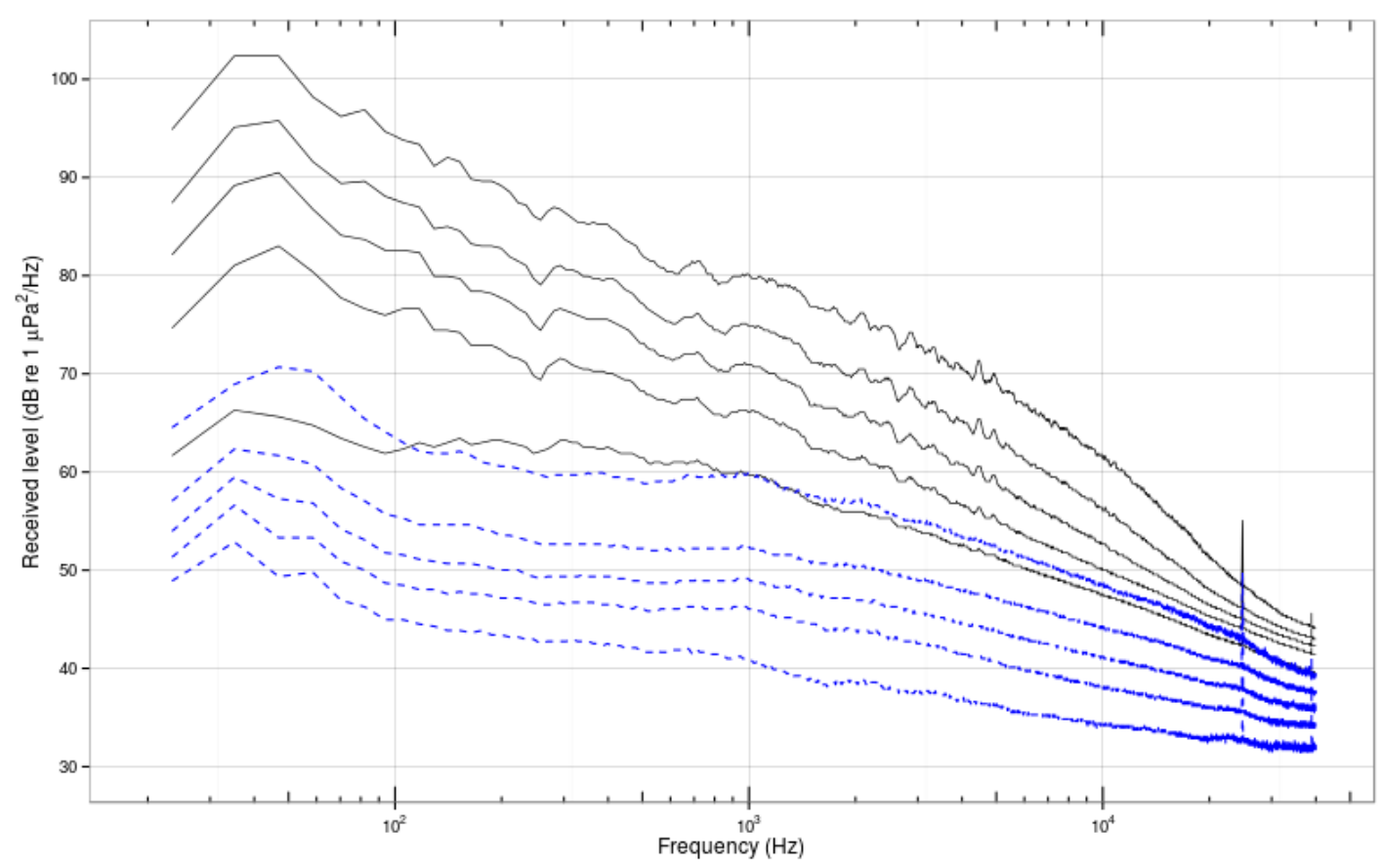

Figure 3. Quantiles $(5,25,50,75, \& 95 \%)$ of background spectrum level $\left(R L_{B}\right.$, dashed blue lines) and total received spectrum level for the entire ship population $\left(R L_{T}\right.$, solid black lines). 


\section{Received spectra}

Most ships transiting Haro Strait raise background noise levels in the core summertime habitat of SRKWs at all measured frequencies (Figure 3). Specifically, 95\% of the ships generate received spectrum levels at or above the $95 \%$ quantile of background levels from $20-96,000 \mathrm{~Hz}$. Thus, at ranges of a couple kilometers, commercial ships cause significant underwater noise pollution not only at low frequencies, but also at high-frequencies.

The difference in median spectrum levels between ship and background noise levels is more than $30 \mathrm{~dB}$ below $100 \mathrm{~Hz}$ and gradually decreases to about $10 \mathrm{~dB}$ at 20,000 $\mathrm{Hz}$. In the high frequency range of 20,000-96,000 Hz the median ship noise is elevated above median background spectrum levels by at least $5 \mathrm{~dB}$. This significant elevation of background levels at high frequencies is what motivated us to account for absorption when computing ship source levels and is consistent with an observation by Hildebrand et al. (2006) of a single commercial ship in Haro Strait at a range of $442 \mathrm{~m}$ that elevated the ambient noise spectrum levels by as much as $30-40 \mathrm{~dB}$ across a broad band of the spectrum $(60-75,000 \mathrm{~Hz})$.

If we define the 5\% quantile of background noise as an "ancient" ambient condition (Clark et al., 2009) then the typical (median) modern ship raises spectrum noise levels above ancient levels by $12-17 \mathrm{~dB}$ at frequencies used in killer whale echolocation $(20,000-70,000 \mathrm{~Hz})$ and by $17-35 \mathrm{~dB}$ at frequencies used in killer whale social vocalization $(200-20,000 \mathrm{~Hz})$. In the frequency range used by vocalizing baleen whales $(20-200 \mathrm{~Hz})$, the median ship spectrum noise levels are about 32-35 dB above the ancient ambient levels.

We gain additional confidence in the accuracy of our sound pressure levels (and implicitly our system calibration) by comparing the received spectrum levels in Figure 3 with ambient noise spectra from other studies. Our background quantiles are bracketed by the average deep-water ambient noise levels associated with sea state 1 to 3 , though the slope of our median curve from $1,000-10,000 \mathrm{~Hz}$ is $-8 \mathrm{~dB} / \mathrm{dec}$ de, about half as steep as the open-ocean slope of $-17 \mathrm{~dB} /$ decade Urick (1983). The "usual lowest ocean noise" curve of Cato depicted in Plate 5 of National Research Council et al. (2003) is bounded by our 5\% and $25 \%$ quantiles from about 30 to $10,000 \mathrm{~Hz}$. Two ambient noise spectra obtained in Haro Strait by Hildebrand et al. (2006) have levels that are bounded by our 5\% and 95\% quantiles of background noise from $300 \mathrm{~Hz}$ to $30,000 \mathrm{~Hz}$. The single ship spectrum $(60 \mathrm{~Hz}$ to $75,000 \mathrm{~Hz})$ obtained opportunistically by Hildebrand et al. (2006) at a range of $442 \mathrm{~m}$ has levels that are greater than our $75 \%$ quantile of $R L_{B}$ at all frequencies.

Similarly, our quantiles of total received spectrum level are consistent with previous studies. For example, the noise spectrum levels recorded in U.S. bays and harbors during World War II by Urick (1983) are entirely bounded by our quantiles of $R L_{T}$ from $100 \mathrm{~Hz}$ to $10,000 \mathrm{~Hz}$. The peak levels (at about 
$50 \mathrm{~Hz}$ ) of the shipping contribution to deep water ambient noise estimated by Ross (1976) for "remote, light, moderate, and heavy" traffic are approximately $71,77,85$, and $95 \mathrm{~dB}$, respectively; the upper three traffic levels are encompassed by our 5\% and 95\% quantiles, while the "remote" levels are no more than $2 \mathrm{~dB}$ below our $5 \%$ quantile. Finally, the quantiles of unweighted received spectrum levels in Bassett et al. (2012) peak near $50 \mathrm{~Hz}$ and have levels that are within about $5 \mathrm{~dB}$ of our levels for corresponding quantiles at all frequencies common to the two studies. Even at high-frequencies our data are consistent; Knudsen et al. (1948) reported total received levels of $40-50 \mathrm{~dB}$ at $30,000 \mathrm{~Hz}$ in coastal waters, a range which brackets our quantiles at that frequency.

\section{Source spectra}

Median source spectra for the whole ship population are shown in Figure 4 as spectrum, 1/12-octave, and 1/3-octave levels, with and without accounting for absorption. For the spectrum levels, we also present $25 \%$ and $75 \%$ quantiles.

\section{Source spectrum levels without absorption}

The median spectrum levels peak near $50 \mathrm{~Hz}$ at about $154 \mathrm{~dB}$ and decrease at higher frequencies with a slope of about $-15 \mathrm{~dB}$ per decade (from $50-40,000 \mathrm{~Hz}$ ). The $25 \%$ and $75 \%$ quantiles are $3-5 \mathrm{~dB}$ from the median below about $10,000 \mathrm{~Hz}$, but at higher frequencies the difference decreases to about $1 \mathrm{~dB}$ re. In the region between 700 and 40,000 $\mathrm{Hz}$ the median spectrum has a subtle slope break near 5,000 Hz, with a slope of about -10 below and about -20 above.

Previous observations, models, and experimental results all help contextualize these whole-population spectrum levels. Unfortunately, many previous studies of ship noise are not comparable due to presenting species-specific band levels (e.g. Hatch et al. 2012) or band levels rather than spectrum levels, or other limitations: small sample size, non-overlapping frequency ranges, and ship classes with low diversity, distinct definitions, or incomparable ships (e.g. ice breakers in Erbe and Farmer 2000).

One exception that allows comparison up to $1,200 \mathrm{~Hz}$ is the analysis of 54 ships at ranges of 360 1,800 $\mathrm{m}$ by Wales and Heitmeyer (2002). Their measured average source spectrum levels are bounded by our $25 \%$ and $75 \%$ quantiles from $400-1200 \mathrm{~Hz}$. At lower frequencies (below $400 \mathrm{~Hz}$ ) their mean levels exceed our $75 \%$ quantile by $2-20 \mathrm{~dB}(20 \mathrm{~dB}$ at $20 \mathrm{~Hz} ; 5 \mathrm{~dB}$ at $50 \mathrm{~Hz}$; and $2 \mathrm{~dB}$ at $100 \mathrm{~Hz})$. Interestingly, their curve does not peak near $50 \mathrm{~Hz}$, but instead continues rising as the frequency decreases to $30 \mathrm{~Hz}$, the lowest frequency they measured. The slope of their mean curve is about $-30 \mathrm{~dB} /$ decade below $100 \mathrm{~Hz}$, and $-20 \mathrm{~dB} /$ decade above. They note that the variance around their mean levels decreases with rising frequency from a standard deviation as high as $5.32 \mathrm{~dB}$ below $400 \mathrm{~Hz}$ to about $3.12 \mathrm{~dB}$ above it. This suggests that a partial explanation for the elevation of their mean values relative to our $75 \%$ quantile may be variability in low-frequency power between ships. 
Models of ship noise that output spectrum levels provide another point of comparison. Our $50 \%$ and 75\% quantiles are encompassed in the spectrum levels presented by National Research Council et al. (2003) for 3 classes of tankers, as well as merchant and fishing classes, based on the RANDI model (Wagstaff, 1973; Breeding et al., 1994) parameterized with data from Emery et al. (2001) and Mazzuca (2001). The 25\% quantile is also encompassed, except below $30 \mathrm{~Hz}$. Below $300 \mathrm{~Hz}$, our median values lie between the fishing and merchant class levels of National Research Council et al. (2003); at higher frequencies - up to $1,000 \mathrm{~Hz}$, the upper limit of their estimates - our median values are above their merchant class but below their intermediate tanker class (length 153-214 m, speed 7.7-9.3 m/s). Overall, this comparison suggests that our median source level spectra validate the RANDI model as parameterized in National Research Council et al. (2003) at intermediate frequencies (100-1,000 Hz), but below $100 \mathrm{~Hz}$ our median levels are lower (by about 5-30 dB) than the RANDI model predicts for all classes except fishing vessels (length and speed bins of 15-46 m, 3.6-5.1 m/s).

Other noticeable differences between our population median spectrum levels and those modeled in National Research Council et al. (2003) are the frequency of the peak power, the general slope of the spectra above the peak, and secondary peaks resolved in our data. While our spectra peak near $50 \mathrm{~Hz}$, the peak power in the spectra of National Research Council et al. (2003) occurs slightly lower, at $30 \mathrm{~Hz}$. Between 100 and $1,000 \mathrm{~Hz}$, the slope of our median spectrum is $-12 \mathrm{~dB}$ per decade, nearly three times less steep than the slope of $-35 \mathrm{~dB}$ per decade in National Research Council et al. (2003). Our spectrum levels have detailed structure where the RANDI model curves of National Research Council et al. (2003) are smooth. Our quantiles show secondary power peaks between 80 and $1,100 \mathrm{~Hz}$ and many narrowband peaks in $1,100-10,000 \mathrm{~Hz}$ range, similar to the frequency dependence of spectral line complexity observed by Wales and Heitmeyer (2002).

Experiments with cavitation provide a final comparison with our whole-population spectrum levels. Above $5,000 \mathrm{~Hz}$ the slope of our median spectrum matches the slope observed during cavitation of a spinning rod (Mellen, 1954) and a water jet (Jorgensen, 1961) - -20 dB per decade, (or -6 dB per octave).

\section{Source spectrum levels with absorption}

The spectrum levels with absorption are indistinguishable from those without absorption below about $5,000 \mathrm{~Hz}$. At higher frequencies, the $S L_{a}$ median spectrum level curve diverges from the $S L$ curve, and starts to rise rapidly at the $40,000 \mathrm{~Hz}$ cut-off of this study. The associated $25 \%$ and $75 \%$ quantiles are within $3-5 \mathrm{~dB}$ of the median values throughout the region of divergence.

These alternative source spectra look unfamiliar at high frequencies, and are not consistent with available data taken close (less than $500 \mathrm{~m}$ ) to ships. For example, the single container ship measured at a range of $442 \mathrm{~m}$ by Hildebrand et al. (2006) in Haro Strait has a absorption-corrected source spectrum 
level of $108 \mathrm{~dB}$ re $1 \mu \mathrm{Pa}^{2} / \mathrm{Hz} @ 1 \mathrm{~m}$ at $40,000 \mathrm{~Hz}$ - about $17 \mathrm{~dB}$ below our $S L_{a}$ spectrum level at that frequency.

However, we believe the absorption-corrected spectra in Figure 4 are rooted in accurate physics and we note that the spectrum levels of $S L_{a}$ are in agreement with some measurements of underwater noise radiated during fully developed cavitation. For example, Lesunovskii and Khokha (1968) specify rotating bar noise spectrum levels of $95-115 \mathrm{~dB}$ at $10,000 \mathrm{~Hz}$ while our $25 \%$ to $75 \%$ quantiles of $S L_{a}$ spectrum level at that frequency are 114-120 dB. Similarly, Blake et al. (1977) report noise levels from a cavitating hydrofoil of $75-110 \mathrm{~dB}$ re $1 \mu \mathrm{Pa}^{2} / \mathrm{Hz} @ 1 \mathrm{yd}$ at $31,500 \mathrm{~Hz}$ which is approaching our $25 \%$ to $75 \%$ quantiles of $S L_{a}$ at that frequency $\left(120-125 \mathrm{~dB}\right.$ re $\left.1 \mu \mathrm{Pa}^{2} / \mathrm{Hz} @ 1 \mathrm{~m}\right)$.

We expect that propeller cavitation noise intensity will be greater than laboratory measurements due to increased length scale and number of the blades on ships. Evidence from World War II studies of torpedo and submarine noise attributed to cavitation supports this expectation. Figures 10.21-10.23 of Urick (1983) show levels equivalent to or bracketing our $S L_{a}$ spectrum levels: $24,000 \mathrm{~Hz}$ spectrum levels of $118 \mathrm{~dB}$ re $1 \mu \mathrm{Pa}^{2} / \mathrm{Hz} @ 1 \mathrm{yd}$ for a submarine cruising at $8 \mathrm{knots}(4 \mathrm{~m} / \mathrm{s})$ near periscope depth; $25,000 \mathrm{~Hz}$ spectrum levels of 100-130 dB re $1 \mu \mathrm{Pa}^{2} / \mathrm{Hz} @ 1 \mathrm{yd}$ for torpedos moving at 20-45 knots (10-23 m/s); and $20,000 \mathrm{~Hz}$ spectrum levels of $115-130 \mathrm{~dB}$ re $1 \mu \mathrm{Pa}^{2} / \mathrm{Hz} @ 1 \mathrm{yd}$ for a suite of torpedoes.

\section{Source 1/12- and 1/3-octave levels}

The median 1/12- and 1/3-octave level curves in Figure 4 are elevated relative to the median spectrum levels and diverge from them above $50 \mathrm{~Hz}$ due to the integration of spectrum levels over bands that get progressively wider with increasing center frequency. Like the spectrum levels, these curves have a peak near $50 \mathrm{~Hz}$. Peak values are $158 \mathrm{~dB}$ re $1 \mu \mathrm{Pa}^{2}$ per band @ $1 \mathrm{~m}$ for the $1 / 12$-octave levels and $163 \mathrm{~dB}$ for the 1/3-octave levels. Above $50 \mathrm{~Hz}$, both curves have slopes of about $-4 \mathrm{~dB} /$ decade from 100-5,000 Hz, $-10 \mathrm{~dB} /$ decade from 5,000-40,000 Hz.

While we are unaware of a comparable aggregation of source spectra from multiple ship classes presented as 1/3-octave levels, there are many studies of individual ships or classes that present $1 / 3$-octave source levels. We compare them here with the median 1/3-octave curve for our ship population because we present only spectrum levels when assessing inter- and intra-class differences in subsequent sections.

Our median 1/3-octave levels are entirely bounded by the estimated levels for 6 diverse ship types presented in Figure 3.14 of Malme et al. (1989) at all comparable frequencies (20-16,000 Hz). Similarly, our levels are within the estimated 1/3-octave source levels $(10-10,000 \mathrm{~Hz})$ summarized in Figure 6.5 of Richardson et al. (1995) for an ice breaker, a composite of supertankers, and a tug/barge at almost all frequencies. Only above about $2,000 \mathrm{~Hz}$ is our median curve slightly below comparable vessels described by Richardson et al. (1995): ours is within $2 \mathrm{~dB}$ of their tug/barge levels, and no more than $10 \mathrm{~dB}$ below 
their supertanker levels. Overall, we find the consistency of our results with these two studies to be remarkable.

Comparing our median curve with the 7 ships (representing five of our classes) for which McKenna et al. (2012) presented 1/3-octave levels, our levels are 5-10 dB lower at all common frequencies $(20-1,000 \mathrm{~Hz})$. As discussed when presenting spectrum levels, we are not sure how to account for this difference, other than to recognize key differences between the studies: distinct transmission loss, our much larger sample size, and our higher diversity of classes.

Studies of ship noise in which speed was varied present a range of levels that is also consistent with our results. Compared with the maximum-minimum envelopes of 1/3-octave source levels (referenced to 1 yard) from 6 cruise ships presented by Kipple (2002) our 1/3-octave levels are within the envelope for both $10 \mathrm{knot}(5 \mathrm{~m} / \mathrm{s})$ and 14-19 knot (7.2-9.8 m/s) samples, except below $25 \mathrm{~Hz}$ where our levels are lower by 1-7 dB. Our levels also fall within (but near the lower edge) of the range of $1 / 3$-octave spectra reported by Arveson and Vendittis (2000) for a bulk carrier tested from 68-148 rpm.

Our 1/3-octave levels help validate the RANDI model used by Erbe et al. (2012) to compute 1/3-octave spectra for five ship length classes over a range of speeds observed in traffic off the coasts of British Columbia and Washington State. Overall, our median levels are entirely within the range of their estimated levels at all modeled frequencies $(10-2,000 \mathrm{~Hz})$. More specifically, though, our median crosses their size-specific curves, because it has a less steep slope. Below $400 \mathrm{~Hz}$ our levels are bounded by their L1 and L3 classes (representing lengths less than $50 \mathrm{~m}$ ); above $400 \mathrm{~Hz}$ our median levels are between their L4 and L5 classes (greater than $50 \mathrm{~m}$ ).

An even more dramatic crossing of model curves by our median $1 / 3$ octave source spectrum level curve is evident upon comparison with Figure 1 of Williams et al. (2014). While our median source levels are equivalent to or bounded by the 1/3-octave levels for each of their modeled ship types (tug, cruise ship, container ship) near or below $250 \mathrm{~Hz}$, at higher frequencies our levels exceed the modeled ones by 7-10 dB.

The crossing of such modeled spectra by our 1/3-octave median curve is one manifestation of a subtle slope difference between our results and previous studies (Arveson and Vendittis, 2000; Kipple, 2002; Erbe et al., 2012; Williams et al., 2014). While Arveson and Vendittis (2000) observe slopes from above a $55 \mathrm{~Hz}$ cavitation "hump" up to about $30,000 \mathrm{~Hz}$ to be $-10 \mathrm{~dB} /$ decade on a 1/3-octave plot, our slope over the same frequency range is shallower $(-6.5 \mathrm{~dB} / \mathrm{decade})$ and we observe a slope break near 3,000 $\mathrm{Hz}$. Below the break the slope is about $-4.5 \mathrm{~dB} /$ decade, while above it is $-10 \mathrm{~dB} / \mathrm{dec}$ de.

The similarity of our 1/3-octave levels with those from available studies at frequencies below $630 \mathrm{~Hz}$ (the lowest tone used in our transmission loss experiment) is the first evidence that our measurements of 
low-frequency radiated noise are accurate. The lower slope relative to other studies suggests that the ship population in this study is generating proportionally more high-frequency noise than ships in previous studies.

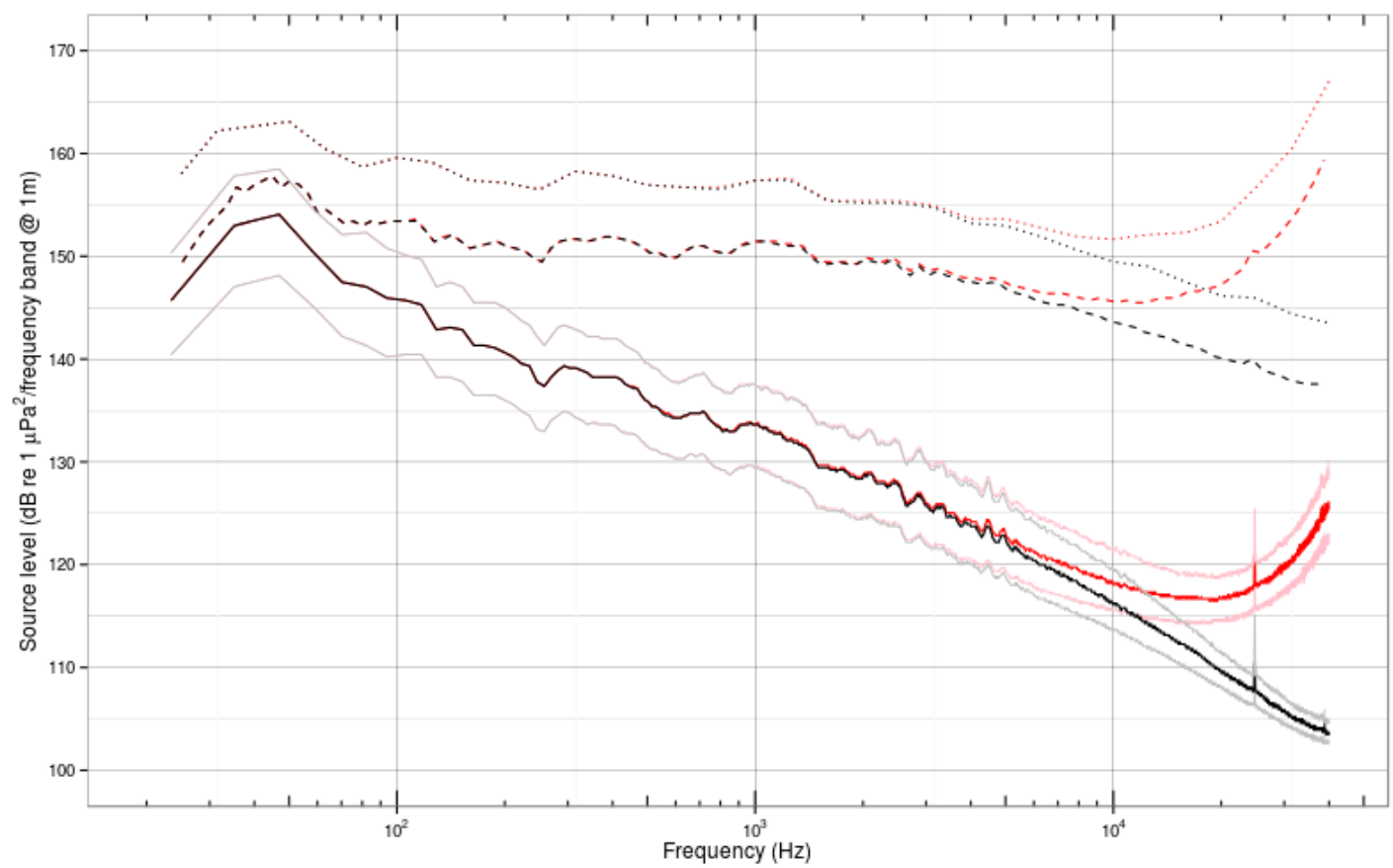

Figure 4. Source level (SL) spectra of the entire ship population in $1 \mathrm{~Hz}$ (solid), 1/12-octave (dashed), and 1/3-octave bands (dotted). Black curves are medians without absorption; red curves are medians with absorption. For the spectrum levels, we delineate 25 and $75 \%$ quantiles in lighter tones. Levels with absorption start to increase rapidly above $15,000-20,000 \mathrm{~Hz}$ for both the 1/12- and 1/3-octave bands.

\section{Source 1/12- and 1/3-octave levels with absorption}

As with the spectrum levels, the 1/12- and 1/3-octave level curves with absorption are indistinguishable from those without absorption below 5,000 Hz. At higher frequencies, the $S L_{a}$ median 1/12- and 1/3octave levels rise to match the $50 \mathrm{~Hz}$ levels of the associated median $S L$ curves near $35,000 \mathrm{~Hz}$ and then continue to increase at higher frequencies.

This means that when we account for absorption when computing 1/12- or 1/3-octave levels, modern ships radiate noise in high-frequency bands (centered near $35,000 \mathrm{~Hz}$ ) at levels equivalent to the lowfrequency maxima near $50 \mathrm{~Hz}$. This surprising equivalency, and the theoretically even higher power levels in bands above $35,000 \mathrm{~Hz}$, are important to consider when assessing the masking potential of ship noise in habitats close to or within shipping lanes for marine species that utilize high-frequency signals. Though it is novel to state that ship noise source levels have peak power at high- as well as low-frequencies, we provide these 1/12- and 1/3-octave noise levels to facilitate accurate modeling of acoustic impacts for species that have critical bands overlapping these octave bands (Richardson et al., 1995). 
While the median 1/12-octave source levels reported by Erbe and Farmer (2000) for the cavitating propeller of an ice breaker are not comparable to any of our ship classes (and much higher - $30 \mathrm{~dB}$ re $1 \mu \mathrm{Pa}^{2}$ per band @ $1 \mathrm{~m}$ above our median level at their power peak near $500 \mathrm{~Hz}$ ), we note that the slope of their median curve is $-13 \mathrm{~dB} / \mathrm{dec}$ ade from 1,000-10,000 Hz. Importantly, Erbe and Farmer (2000) is rare in stipulating that absorption was accounted for in computing source levels. Their slope is about twice as steep as our 1/12-octave median slope of $-7 \mathrm{~dB} /$ decade in the same frequency range.

Finally, Kipple (2002) did not correct for absorption, but made measurements of cruise ship receive levels up to $40,000 \mathrm{~Hz}$ at short range (500 yards) and therefore provides a rare point of reference for our high-frequency $S L_{a}$ levels. Their 1/3-octave band source levels at $40,000 \mathrm{~Hz}$ for a suite of cruise ships and speeds (10-19 knots; 5.1-9.7 m/s) vary from 133-154 dB re $1 \mu \mathrm{Pa} @ 1$ yard - values that approximately bracket our uncorrected $S L$ levels but are 13-34 dB below our $S L_{a}$ levels.

\section{Spectral differences between ship classes}

When the ship population is broken down by class (Figure 5) the medians show a striking bifurcation. While all classes have similar median spectrum levels near $20,000 \mathrm{~Hz}$, the curves diverge at lower frequencies, and below $200 \mathrm{~Hz}$ they bifurcate into high- and low-power groups. The high-power group has peak power of 153-159 dB near $50 \mathrm{~Hz}$ (just above the population median shown in Figure 4) and consists of container ships, vehicle carriers, cargo ships, bulk carriers, and tankers. The low-power group has peak power of 134-141 dB near $50 \mathrm{~Hz}$ or just above $100 \mathrm{~Hz}$ - levels well below the population median or even $25 \%$ quantile - and consists of passenger vessels, tugs, military, research, fishing, miscellaneous, and pleasure vessels.

The $25 \%$, median, and $75 \%$ spectrum levels at the power peak near $50 \mathrm{~Hz}$ in Figure 4 bracket the $50 \mathrm{~Hz}$ levels of the high-power group of ships in Figure 5. The median of the whole population is most similar to the spectra in the high-power group (e.g. the bulk carrier curve) because the aggregated sample size is much higher in the high-power group than in the low-power one (see Table 2). Modelers interested in assessing impacts of specific ship classes, particularly those in the lower-power group, should not use the median or $25 \%$ quantile levels for the whole population, but instead select class-specific levels from the curves in Figure 5.

Container ships have the highest median source spectrum level of all classes at almost all frequencies below $10,000 \mathrm{~Hz}$ with peak power of $159 \mathrm{~dB}$ near $40 \mathrm{~Hz}$. This is likely because of their relatively large size and high mean speed $(10 \mathrm{~m} / \mathrm{s})$ compared to pleasure craft or military ships - the classes with the lowest median power at all frequencies below $400 \mathrm{~Hz}$.

Many of the ship classes show secondary peaks in the median spectrum levels from 100-5,000 Hz. For example, most classes show a $2 \mathrm{~dB}$ dip near $250 \mathrm{~Hz}$ and at least container ships, vehicle carriers, cargo 


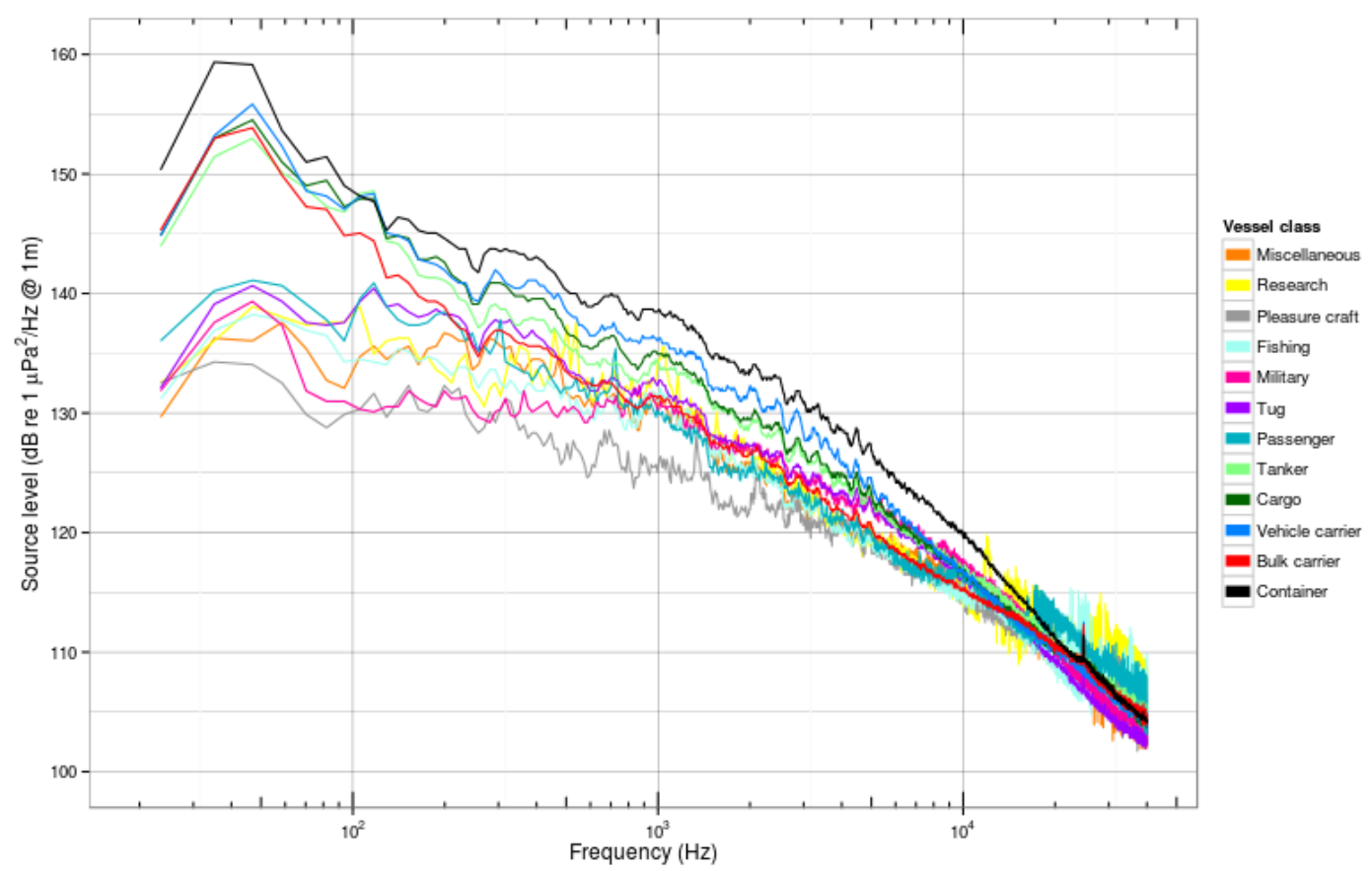

Figure 5. Comparison of median source spectrum levels (without absorption) between ship classes.

ships, and tankers have peaks near 300, 700, and 1,000 Hz. There are also narrower peaks for these same classes between 1,000-10,000 Hz, most prominently at 2,000 Hz and near 3,000 Hz.

The variability of the median source level in each class decreases above 5,000 Hz and remains low until about 10,000 Hz. At higher frequencies $(10,000-40,000 \mathrm{~Hz})$ the variability increases again for most ship classes, but the degree of increase is a strong function of sample size within a class. While we know from examining spectrograms from individual ships that some of the narrow peaks are associated with active acoustic sources (depth sounders, scientific echosounders, and fish finders), in Figure 5 the high variance above $10,000 \mathrm{~Hz}$ is due primarily to some ships having spectrum levels that do not meet the robust threshold at higher frequencies. Particularly in classes where the sample size is already small this leads to some high frequency bins having many fewer data points than adjacent bins which in turn results in more-variable median values across this high-frequency range.

The quantiles of source spectrum level by class in Figure 6 provide further detail about inter-class differences. Comparing the $95 \%$ quantiles, container ships still have the highest peak power $(165 \mathrm{~dB})$ near $50 \mathrm{~Hz}$, but bulk and vehicle carriers, cargo ships and tankers also have peak power greater than $160 \mathrm{~dB}$. Other classes have peak power in the $95 \%$ quantiles near $50 \mathrm{~Hz}$ at spectrum levels that range from $156 \mathrm{~dB}$ (research) to $150 \mathrm{~dB}$ (tugs). Comparing the 5\% quantiles, we expected that the military class would have the lowest levels due to more advanced ship-quieting technologies. While the military class levels are much lower than container ships (10 dB less at $1,000 \mathrm{~Hz}$ and $20 \mathrm{~dB}$ less at $100 \mathrm{~Hz})$, other classes have 
even lower levels at those frequencies, particularly fishing vessels and pleasure craft.

\section{Spectral variability within ship classes}

All classes of ships have spectrum levels that vary more at low frequencies than at high frequencies (Figure 6). Near $50 \mathrm{~Hz}$ there is a 15-35 dB difference between the 5\% and 95\% quantile levels. That difference decreases with rising frequency until above $20,000 \mathrm{~Hz}$ it is typically less than $10 \mathrm{~dB}$.

Below 20,000 Hz, source level variability in Figure 6 tends to be lower for the classes that have smaller speed over ground standard deviations and that have larger sample size as shown in Table 2. While container and cargo ships, bulk and vehicle carriers, and tankers have 95-5\% spectrum level differences of about $15 \mathrm{~dB}$, the other classes exhibit larger differences up to $25-30 \mathrm{~dB}$. The classes with the largest number of vessels are most uniform in their speed over ground and most consistent in their vessel design and operation. Tugs are a special case because there are many transits and their speed is not unusually variable, but their loading is. Our passenger vessels are all cruise ships and hence similar in design, but their speeds are quite variable as they adjust their arrival times in the Port of Vancouver. Finally, the small numbers of pleasure craft and vessels classed as miscellaneous are highly variable in both their designs and their operations.

Other studies have observed a similar pattern of source level variability with frequency. In mean source spectrum levels from 54 ships Wales and Heitmeyer (2002) noted higher, more-variable standard deviations from 30-400 Hz and lower, more-constant ones from 400-1200 Hz. Figure 8 of McKenna et al. (2013) displays histograms of octave-band power for 593 container ships which have widths that decrease from about $35 \mathrm{~dB}$ in the $16 \mathrm{~Hz}$ band to $26 \mathrm{~dB}$ in the $500 \mathrm{~Hz}$ band.

One explanation for this pattern is that the low-frequency portion of ship noise spectra is influenced by diverse design and operational details (many sources of variability), while cavitation generates highfrequency broadband noise (including up to $100,000 \mathrm{~Hz}$ ) no matter its source. As mentioned in the introduction, there are many sources of ship noise below $1,000 \mathrm{~Hz}$ that should be expected to vary between individual ships in a particular class. Conversely, a wide range of vessels have been documented to radiate elevated high-frequency noise upon increased engine RPM or SOG - conditions reasonably associated with increased cavitation (Erbe and Farmer, 2000; Kipple, 2002; Hildebrand et al., 2006).

The literature offers a handful of spectra for particular classes that can be compared with the quantiles of Figure 6. These spectra typically come from individual ships, though, so can only serve to verify the range of our quantiles, rather than assessing the accuracy of the quantiles themselves.

The spectrum levels provided by McKenna et al. (2012) for individual ships in comparable classes (a container ship, a vehicle carrier, two bulk carriers, and a few tankers) all fall within a few $\mathrm{dB}$ of our $95 \%$ quantile. Only their bulk carrier deviates from this pattern with levels near $100 \mathrm{~Hz}$ higher by about $10 \mathrm{~dB}$. 


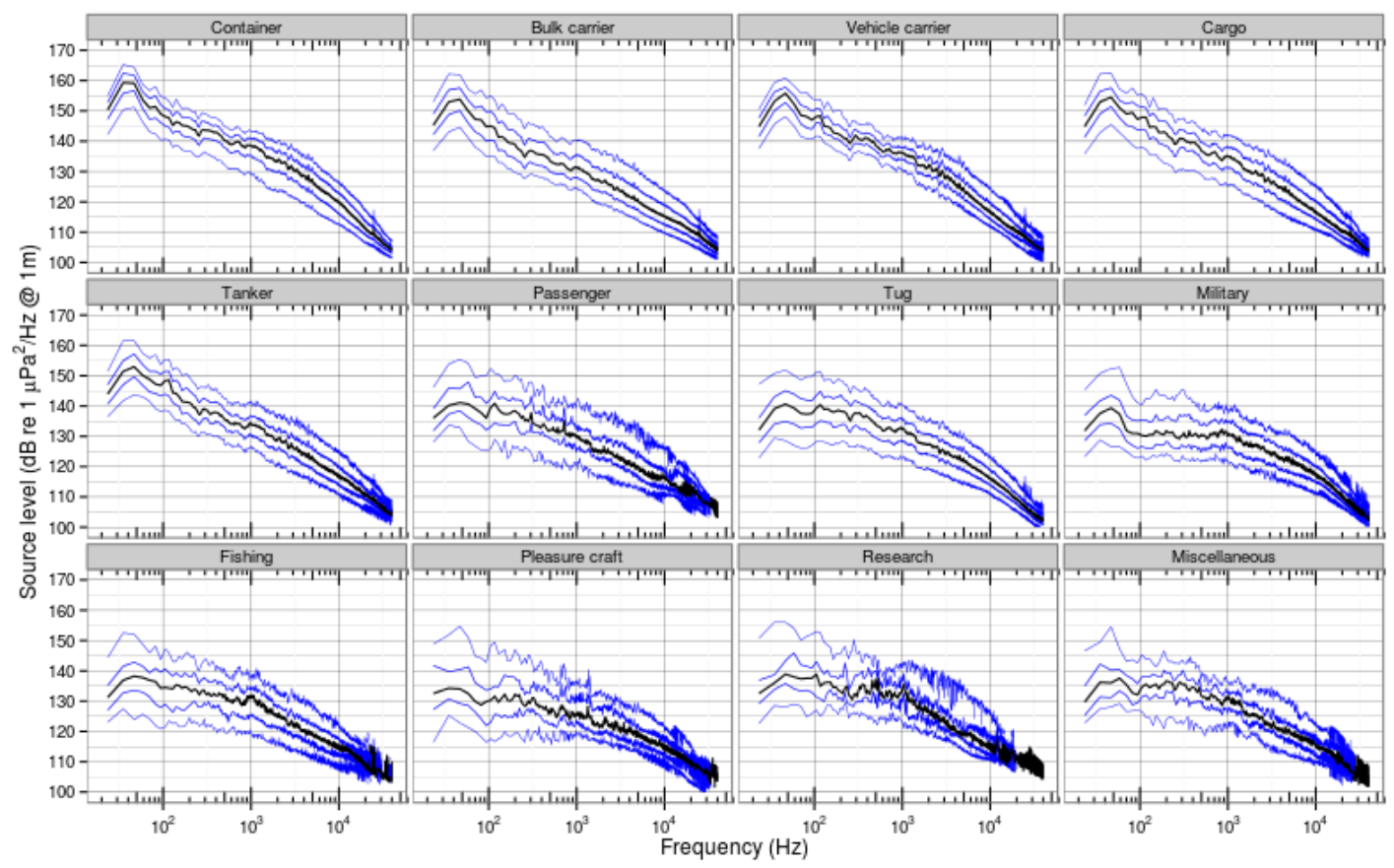

Figure 6. Quantiles of source spectrum levels for each class of ship. Median (50\%) quantile (black) overlies $5,25,75$, and $95 \%$ quantiles (blue).

Overall, the broadband and spectrum levels of ships associated with the port of Los Angeles (McKenna et al., 2012) are most comparable to the noisiest $5 \%$ of ships transiting Haro Strait.

Similarly, the source spectrum levels for a single container ship measured in the middle of Haro Strait by Hildebrand et al. (2006) also fall within the 5\% and 95\% quantiles of our cargo class (from $90 \mathrm{~Hz}$ to 40,000 Hz). The alignment of such individual ship spectra within the quantiles of their associated class at all common frequencies - and most importantly at frequencies below that of our lowest transmission loss test tone - helps verify our extrapolation of the near-spherical spreading we observed from $630-20,100 \mathrm{~Hz}$ to all frequencies reported in our study.

We take this spectral consistency across multiple classes as evidence that the ship noise received at our nearshore hydrophone has not undergone shallow water attenuation. While normal mode theory (Urick, 1983) would predict a cutoff frequency of about $50 \mathrm{~Hz}$ if our hydrophone were in a shallow channel $8 \mathrm{~m}$ deep, that is not the bathymetric situation at our study site. Instead, Haro Strait is a 250-300 m deep channel with a steep western wall of sparsely sedimented solid rock (Jones and Wolfson, 2006) and our hydrophone is positioned near the top of the wall where the offshore bottom slope is 20-30 degrees. In this situation, Jones and Wolfson (2006) expect not only destructive interference at ranges much greater than the source depth, but also upslope enhancement. In our transmission loss experiment, we did not observe any frequency dependent attenuation consistent with these phenomena. Furthermore, the theoretical cutoff frequency for a $250 \mathrm{~m}$ deep channel is $1.5 \mathrm{~Hz}$ (Urick, 1983), well below our lowest measured 
frequency band. We therefore argue that any effects of interference or backscatter are averaged out in our study, primarily because each isolated ship ensonifies the full width of this reverberating channel and moves 150-300 $\mathrm{m}$ during a 30-second recording (1-2 times the $130 \mathrm{~m}$ wavelength or our lowest measured frequency, $11.5 \mathrm{~Hz})$.

\section{CONCLUSIONS}

Having ensured our samples were isolated (uncontaminated by noise from other ships or boats) and subtracted estimated background levels, we are confident that median received levels of ship noise in the core of SRKW critical habitat are elevated above median background levels not only at low frequencies (20-30 dB from 100-1000 Hz), but also at high frequencies (5-13 dB from 10,000-40,000 Hz). Thus, underwater noise radiated by modern ships extends to high frequencies just as boat noise does (Erbe, 2002; Kipple and Gabriele, 2004; Hildebrand et al., 2006). Earlier studies have also observed this aspect of ship noise, but with smaller sample size, over different frequency ranges and less diverse ship classes (Kipple and Gabriele, 2004; Hildebrand et al., 2006; Bassett et al., 2012), and/or in received rather than source levels (Hermannsen et al., 2014).

Such ship noise has the potential to mask odontocete signals, especially in coastal environments where shipping lanes are close enough to the shoreline $(<10 \mathrm{~km})$ that high frequency sound is not fully absorbed. In the summertime habitat of the endangered SRKWs ship noise may interfere not only with SRKW communication (vocalizations) but also foraging and navigation (echolocation clicks).

Average broadband received levels $(11.5-40,000 \mathrm{~Hz})$ for the entire ship population are $110 \pm 7 \mathrm{~dB}$ and ranged from $97 \pm 10 \mathrm{~dB}$ for pleasure craft to $116 \pm 4 \mathrm{~dB}$ for container ships. The range of $R L$ for container ships (112-120 dB) show that levels received by SRKWs along the coastline at Lime Kiln from some container ships occasionally meet or exceed the $120 \mathrm{~dB}$ broadband threshold currently used by NOAA to define level B harassment from non-impulsive noise in the U.S.

Ships northbound in Haro Strait exhibit moderate speeds with low variability ( $S O G$ of $7.3 \pm 2.0 \mathrm{~m} / \mathrm{s}$ or $14.1 \pm 3.9$ knots). Nevertheless, there is enough variation in speed across the whole population to reveal a linear relationship between received level and speed with a slope of $+1.8 \mathrm{~dB}$ per $\mathrm{m} / \mathrm{s}$. This suggests a potential mitigation strategy for the average ship - slowing down - that has been recommended previously as an operational ship quieting option (Southall and Scholik-Schlomer, 2008). This strategy has other environmental benefits, like reducing collision risks, and is consistent with recent industry efforts to increase fuel efficiency (e.g. the "slow steaming" initiative of Maersk). For a passenger ship measured at speeds of 9-18 knots (4.6-9.3 m/s) during WWII Ross (1976) shows in Figure 8.19 that reducing speed lowers source spectrum levels by at about $1.5 \mathrm{~dB} / \mathrm{knot}(2.9 \mathrm{~dB}$ per m/s $)$ at all frequencies, 
but most notably lowers them by about $3.0 \mathrm{~dB} / \mathrm{knot}(5.8 \mathrm{~dB}$ per $\mathrm{m} / \mathrm{s})$ - both at high frequencies (above $10,000 \mathrm{~Hz}$ ) and at low frequencies (less than $100 \mathrm{~Hz}$ ).

Average broadband source levels were $173 \pm 7 \mathrm{~dB}$ for the population. Comparing broadband source levels between ship classes, container ships have the highest mean $S L$ of $178 \pm 4 \mathrm{~dB}$. Therefore, assuming near-spherical transmission loss, marine life within a couple kilometers of shipping lanes will commonly receive noise levels above NOAA's $120 \mathrm{~dB}$ threshold. At ranges less than about a kilometer, receive levels from many ships in Haro Strait will exceed the 130-150 dB modeled ship noise (10-50,000 Hz) dose associated with minor changes in northern resident killer whale behavior (Williams et al., 2014).

At distances of less than about a kilometer, it is likely that received 1/12- or 1/3-octave band levels at high frequencies are equal or greater than they are at low frequencies. Further research should measure ship spectrum levels at ranges of a few hundred meters in order to more fully quantify the high frequency (40,000-100,000 Hz) components of ship sound signatures.

Models of noise impacts in habitat containing shipping lanes will be more accurate if parameterized with spectral data, as opposed to broadband levels. Since we observe spectral variability between and within the 12 classes of vessels in this study, most prominently the bifurcation at low frequencies between classes, such models should use the class-specific spectrum level quantiles if possible, rather than the whole-population spectrum and band level medians we have presented.

Our broadband, spectrum, 1/12-octave, and 1/3-octave source levels for the whole population have median values that are comparable to the literature, with a few exceptions that we believe are due primarily to methodological differences. Some past analyses may not have made all recommended corrections (TC43 Acoustics, 2012); most commonly, methods sections are ambiguous about the definition and subtraction of background noise levels from total received levels prior to source level computations. It is also possible that these exceptions are due to sampling ship populations that are distinct (being composed of different individual ships/classes and/or operating differently). Even though our sample size is larger than most previous studies, we estimate that we sampled only about $1.6 \%$ of the 86,942 ships in the 2012/2013 global fleet (UNCTD, 2013). In any case, since our source level quantiles have slightly lower levels than some studies, particularly at low frequencies, they can be taken as a conservative characterization of the current fleet when developing ship noise models or policies.

One subtle pattern we note is that compared to some previous measurements and models, our median source spectrum levels are relatively low below $200 \mathrm{~Hz}$ and relatively high above 20,000 Hz. One implication of this is that noise models using previous measurements may overestimate the low-frequency noise levels of some ship types and underestimate high-frequency noise levels. Such flattening of the spectral slope in more modern ships is described in Figure 8.20 of Ross (1976) which shows source 
spectrum levels (below $100 \mathrm{~Hz}$ and from 1,000-20,000 Hz) elevated 1-3 dB in large populations of post-War versus WWII-era vessels. Some studies show a flattening of spectra above $100-1,000 \mathrm{~Hz}$ as ship and engine speed increases (Ross, 1976; Arveson and Vendittis, 2000; Kipple, 2002). We speculate that this historical trend may be continuing and recommend further investigation of the evolution of both ship speed (Leaper et al., 2014) and the mitigation of low-frequency internal noise on ships for human health reasons.

We recommend that future ship noise studies statistically characterize populations of ships - both their broadband and spectrum source levels. Having struggled to discern which studies in the literature are comparable to our results, we also suggest that future method sections be explicit about ship classification, calibration procedures, background subtraction and/or criteria for isolation from other sources, models and/or measurements of transmission loss, band width(s) and centers, absorption, and any other corrections. Metadata should include statistical representations of ship speeds and measurement ranges. Many studies are ambiguous about some of these details which complicates replication, comparison of results, and formation of hypotheses about observed differences.

Future work should also assess covariates other than speed, such as size, as well as azimuthal and temporal variability in source spectrum levels. We know from years of listening to live audio streams of Salish Sea ship noise (free via orcasound.net) that there is great temporal variability in the noise radiated by many ships. A small percentage of ships emit periodic strong mid-frequency tones that are likely caused by singing propellers (Ross, 1976). Our next step is to explore such temporal variations in amplitude and frequency, identify statistical outliers that may represent extreme masking cases, and further investigate possible governing variables, including speed, class, azimuth, and loading.

The variability we observe within ship classes indicates opportunities for reducing noise in ships, particularly those associated with the upper quantiles in each class. While the details of the spectral and temporal variability of noise from an individual ship may be important to a receiving species, metrics for measuring and regulating underwater noise will practically involve some temporal averaging, and possibly integration over bands wider than $1 \mathrm{~Hz}$. We suggest a reasonable time scale for averaging ship noise is seconds or minutes, rather than a year as stipulated in the European Union's Marine Strategy Framework Directive 2008/56/EC (Tasker et al., 2010). Additionally, based on the received signal above background noise that we observe at high frequencies, we recommend that future guidelines for monitoring ship noise raise the upper frequency limit of recording systems from 20,000 Hz (Dekeling et al., 2014) to at least 50,000 Hz. As Registered Ship Classification Societies continue to issue underwater radiated noise notations, we hope that these data can be used to assess their validity. 


\section{ACKNOWLEDGMENTS}

We would like to thank all who helped deploy and maintain the calibrated hydrophone system. Logistical support was provided by The Whale Museum (Jenny Atkinson and Eric Eisenhardt), Beam Reach, intrepid divers (David Howitt), and SMRU Consulting. Analysis was accomplished through open-source software and data including: Generic Mapping Tools (GMT), NOAA bathymetry and shipping lanes, Qt, R, ggplot, Libreoffice, Overleaf, and Zotero. Chris Bassett and Marla Holt kindly provided helpful reviews of the pre-print; Michael Jasny and Hussein Alidina helped us understand the policy implications of our work; Leslie Veirs, Wendy Wood, and Annie Reese provided unflinching encouragement throughout. Finally, we thank the libraries of the University of Washington and Friday Harbor Labs for access to otherwise closed-access journals.

\section{REFERENCES}

Aguilar Soto, N., Johnson, M., Madsen, P. T., Tyack, P. L., Bocconcelli, A., and Fabrizio Borsani, J. (2006). Does intense ship noise disrupt foraging in deep-diving Cuvier's beaked whales (Ziphius cavirostris)? Marine Mammal Science, 22(3):690-699.

Andrew, R. K., Howe, B. M., Mercer, J. A., and Dzieciuch, M. A. (2002). Ocean ambient sound: comparing the 1960 s with the 1990s for a receiver off the California coast. Acoustics Research Letters Online, 3(2):65-70.

Arveson, P. T. and Vendittis, D. J. (2000). Radiated noise characteristics of a modern cargo ship. The Journal of the Acoustical Society of America, 107(1):118-129.

Au, W. W., Pack, A. A., Lammers, M. O., Herman, L. M., Deakos, M. H., and Andrews, K. (2006). Acoustic properties of humpback whale songs. The Journal of the Acoustical Society of America, 120(2):1103-1110.

Au, W. W. L., Ford, J. K. B., Horne, J. K., and Allman, K. A. N. (2004). Echolocation signals of free-ranging killer whales (Orcinus orca) and modeling of foraging for chinook salmon (Oncorhynchus tshawytscha). The Journal of the Acoustical Society of America, 115(2):901.

Ayres, K. L., Booth, R. K., Hempelmann, J. a., Koski, K. L., Emmons, C. K., Baird, R. W., BalcombBartok, K., Hanson, M. B., Ford, M. J., and Wasser, S. K. (2012). Distinguishing the Impacts of Inadequate Prey and Vessel Traffic on an Endangered Killer Whale (Orcinus orca) Population. PLoS ONE, 7(6).

Bassett, C., Polagye, B., Holt, M., and Thomson, J. (2012). A vessel noise budget for Admiralty Inlet, Puget Sound, Washington (USA). The Journal of the Acoustical Society of America, 132(6):3706-3719. 
Blake, W. K., Wolpert, M. J., and Geib, F. E. (1977). Cavitation noise and inception as influenced by boundary-layer development on a hydrofoil. Journal of Fluid Mechanics, 80(04):617-640.

Breeding, J. E., Pflug, L. A., Bradley, M., Hebert, M., and Wooten, M. (1994). RANDI 3.1 User's Guide. Technical report, DTIC Document.

Buckstaff, K. C. (2004). Effects of watercraft noise on the acoustic behavior of bottlenose dolphins, Tursiops truncatas, in Sarasota Bay, Florida. Marine Mammal Science, 20(October):709-725.

Cerchio, S., Jacobsen, J. K., and Norris, T. F. (2001). Temporal and geographical variation in songs of humpback whales, Megaptera novaeangliae: synchronous change in Hawaiian and Mexican breeding assemblages. Animal behaviour, 62(2):313-329.

Clark, C. W., Ellison, W., Southall, B., Hatch, L., Van Parijs, S., Frankel, A., and Ponirakis, D. (2009). Acoustic masking in marine ecosystems: intuitions, analysis, and implication. Marine Ecology Progress Series, 395:201-222.

Dekeling, R., Tasker, M., Graaf, S. V. D., Ainslie, M., Andersson, M., André, M., Borsani, J. F., Brensing, K., Castellote, M., Cronin, D., Dalen, J., Folegot, J., Leaper, R., Pajala, J., Redman, P., Robinson, S. P., Sigray, P., Sutton, G., Thomsen, F., Werner, S., Wittekind, D., and Young, J. V. (2014). Monitoring Guidance for Underwater Noise in European Seas-Part II: Monitoring Guidance Specifications. JRC Scientific and Policy Report UR 26555 EN, Publications Office of the European Union, Luxembourg. Dow, M. T., Emling, J. W., and Knudsen, V. O. (1945). Survey of Underwater Sound No. 4: Sounds from Surface Ships. National Defense Research Committee, Div, 6.

Emery, L., Bradley, M., and Hall, T. (2001). Data base description (DBD) for the historical temporal shipping data base (HITS), Version 4.0. Planning Systems Incorporated, pages 1-40.

Erbe, C. (2002). Underwater noise of whale-watching boats and potential effects on killer whales (Orcinus orca), based on an acoustic impact model. Marine Mammal Science, 18(2):394-418.

Erbe, C. (2011). Underwater acoustics: Noise and the effects on marine mammals. Pocketbook, printed by JASCO Applied Sciences, Brisbane, QLD, Australia, 3rd edition.

Erbe, C. and Farmer, D. M. (2000). Zones of impact around icebreakers affecting beluga whales in the Beaufort Sea. The Journal of the Acoustical Society of America, 108:1332.

Erbe, C., MacGillivray, A., and Williams, R. (2012). Mapping cumulative noise from shipping to inform marine spatial planning. The Journal of the Acoustical Society of America, 132(5):EL423-EL428.

Ford, J. K. B. (1987). A catalogue of underwater calls produced by killer whales (Orcinus orca) in British Columbia. Technical report, Department of Fisheies and Oceans.

Ford, J. K. B. and Ellis, G. M. (2006). Selective foraging by fish-eating killer whales. Marine Ecology Progress Series, 316:185-199. 
Francois, R. E. and Garrison, G. R. (1982). Sound absorption based on ocean measurements. Part II: Boric acid contribution and equation for total absorption. The Journal of the Acoustical Society of America, 72(6):1879-1890.

Gray, L. M. and Greeley, D. S. (1980). Source level model for propeller blade rate radiation for the world's merchant fleet. The Journal of the Acoustical Society of America, 67(2):516-522.

Hall, J. D. and Johnson, C. S. (1972). Auditory thresholds of a killer whale Orcinus orca Linnaeus. The Journal of the Acoustical Society of America, 51(2B):515-517.

Hanson, M. B., Baird, R. W., Ford, J. K. B., Hempelmann-Halos, J., Van Doornik, D., Candy, J., Emmons, C. K., Gregory Schorr, Brian Gisborne, Katherine Ayres, Samuel Wasser, Kelley Balcomb-Bartok, John Sneva, and Michael Ford (2010). Species and stock identification of prey consumed by endangered southern resident killer whales in their summer range. Endangered Species Research, 11:69-82.

Hatch, L. T., Clark, C. W., Van Parijs, S. M., Frankel, A. S., and Ponirakis, D. W. (2012). Quantifying loss of acoustic communication space for right whales in and around a U.S. National Marine Sanctuary. Conservation Biology.

Hauser, D. D. W., Logsdon, M. G., Holmes, E. E., VanBlaricom, G. R., and Osborne, R. W. (2007). Summer distribution patterns of southern resident killer whales Orcinus orca: core areas and spatial segregation of social groups. Marine Ecology Progress Series, 351:301-310.

Hermannsen, L., Beedholm, K., Tougaard, J., and Madsen, P. T. (2014). High frequency components of ship noise in shallow water with a discussion of implications for harbor porpoises (Phocoena phocoena). The Journal of the Acoustical Society of America, 136(4):1640-1653.

Hildebrand, J., McDonald, M. A., Calambokidis, J., and Balcomb, K. (2006). Whale watch vessel ambient noise in the Haro Strait. Technical Report MPL TM-490.

Hildebrand, J. A. (2009). Anthropogenic and natural sources of ambient noise in the ocean. Marine Ecology Progress Series, 395:5-20.

Holt, M. M., Noren, D. P., Veirs, V., Emmons, C. K., and Veirs, S. (2009). Speaking up: Killer whales (Orcinus orca) increase their call amplitude in response to vessel noise. The Journal of the Acoustical Society of America, 125(1).

Jones, C. D. and Wolfson, M. A. (2006). Acoustic environment of Haro Strait: Preliminary propagation modeling and data analysis. Technical report, DTIC Document.

Jorgensen, D. W. (1961). Noise from Cavitating Submerged Water Jets. The Journal of the Acoustical Society of America, 33(10):1334-1338.

Kipple, B. (2002). Southeast Alaska Cruise Ship Underwater Acoustic Noise. Technical Report NSWCCD71-TR-2002/574, Naval Surface Warfare Center - Detachment Bremerton. 
Kipple, B. and Gabriele, C. (2004). Underwater noise from skiffs to ships. In Proc. of Glacier Bay Science Symposium.

Knudsen, V. O., Alford, R. S., and Emling, J. W. (1948). Underwater ambient noise. J. Mar. Res., 7.

Leaper, R., Renilson, M., and Ryan, C. (2014). Reducing underwater noise from large commercial ships: current status and future directions. Journal of Ocean Technology, 9(1). 00004.

Lesunovskii, V. P. and Khokha, Y. V. (1968). Characteristics of the noise spectrum of hydrodynamic cavitation on rotating bars in water. Akust. Zh, 14:566-571.

Malme, C. I., Miles, P. R., and McElroy, P. T. (1982). The acoustic environment of humpback whales in Glacier Bay and Frederick Sound/Stephens Passage, Alaska. Bolt, Baranek, and Newman, Inc. 4848, NMFS/MML.

Malme, C. I., Miles, P. R., Miller, G. W., Richardson, W. J., Roseneau, D. J., Thomson, D. H., and Greene Jr, C. R. (1989). Analysis and ranking of the acoustic disturbance potential of petroleum industry activities and other sources of noise in the environment of marine mammals. Technical Report 6945, BBN Systems and Technologies Corporation.

Mazzuca, L. L. (2001). Potential effects of low frequency sound (LFS) from commercial vessels on large whales. PhD thesis, University of Washington.

McDonald, M. A., Hildebrand, J. A., and Wiggins, S. M. (2006). Increases in deep ocean ambient noise in the Northeast Pacific west of San Nicolas Island, California. The Journal of the Acoustical Society of America, 120(2):711-718.

McKenna, M. F., Ross, D., Wiggins, S. M., and Hildebrand, J. A. (2012). Underwater radiated noise from modern commercial ships. The Journal of the Acoustical Society of America, 131(1):92-103.

McKenna, M. F., Wiggins, S. M., and Hildebrand, J. A. (2013). Relationship between container ship underwater noise levels and ship design, operational and oceanographic conditions. Scientific Reports, 3.

Melcon, M. L., Cummins, A. J., Kerosky, S. M., Roche, L. K., Wiggins, S. M., and Hildebrand, J. A. (2012). Blue whales respond to anthropogenic noise. PloS one, 7(2).

Mellen, R. H. (1954). Ultrasonic Spectrum of Cavitation Noise in Water. The Journal of the Acoustical Society of America, 26(3):356-360.

Merchant, N. D., Pirotta, E., Barton, T. R., and Thompson, P. M. (2014). Monitoring ship noise to assess the impact of coastal developments on marine mammals. Marine Pollution Bulletin, 78(1-2):85-95.

Mooney, T. A., Yamato, M., and Branstetter, B. K. (2012). Hearing in cetaceans: from natural history to experimental biology. In Advances in Marine Biology, volume 63, pages 197-246. Academic Press.

Morisaka, T., Shinohara, M., Nakahara, F., and Akamatsu, T. (2005). Effects of ambient noise on the 
whistles of Indo-Pacific bottlenose dolphin populations. Journal of Mammalogy, 86(3):541-546.

Munger, L. M., Wiggins, S. M., Moore, S. E., and Hildebrand, J. A. (2008). North Pacific right whale (Eubalaena japonica) seasonal and diel calling patterns from long-term acoustic recordings in the southeastern Bering Sea, 2000-2006. Marine Mammal Science, 24(4):795-814.

National Research Council, Committee on Potential Impacts of Ambient Noise in the Ocean on Marine Mammals, Ocean Studies Board, and Division on Earth and Life Studies (2003). Ocean Noise and Marine Mammals. National Academies Press.

Richardson, W. J., Greene Jr, C. R., Malme, C. I., and Thomson, D. H. (1995). Marine Mammals and Noise. Academic Press, New York.

Riesch, R., Ford, J., and Thomsen, F. (2006). Stability and group specificity of stereotyped whistles in resident killer whales, Orcinus orca, off British Columbia. Animal Behaviour, 71(1):79-91.

Rolland, R. M., Parks, S. E., Hunt, K. E., Castellote, M., Corkeron, P. J., Nowacek, D. P., Wasser, S. K., and Kraus, S. D. (2012). Evidence that ship noise increases stress in right whales. Proceedings of the Royal Society B: Biological Sciences.

Ross, D. (1976). Mechanics of underwater noise. Pergamon Press.

Southall, B. L., Bowles, A. E., Ellison, W. T., Finneran, J. J., Gentry, R. L., Greene Jr, C. R., Kastak, D., Ketten, D. R., Miller, J. H., and Nachtigall, P. E. (2007). Marine mammal noise exposure criteria: Initial scientific recommendations. Aquatic Mammals, 33(4):411-509.

Southall, B. L. and Scholik-Schlomer, A. (2008). Potential application of vessel-quieting technology on large commercial vessels. In Final Report of the National Oceanic and Atmospheric Administration (NOAA) International Conference. 1-2 May, 2007, NOAA Fisheries, Silver Spring, MD.

Stimpert, A. K. (2010). Non-song sound production and its behavioral context in humpback whales (Megaptera novaeangliae). PhD thesis, University of Hawaii.

Szymanski, M. D., Bain, D. E., Kiehl, K., Pennington, S., Wong, S., and Henry, K. R. (1999). Killer whale (Orcinusorca) hearing: Auditory brainstem response and behavioral audiograms. Journal of the Acoustical Society of America, 106(2):1134-1141.

Tasker, M. L., Amundin, M., Andre, M., Hawkins, A., Lang, W., Merck, T., Scholik-Schlomer, A., Teilmann, J., Thomsen, F., Werner, S., and others (2010). Marine Strategy Framework Directive (Task Group 11 Report) Underwater noise and other forms of energy. Report No. EUR, 24341.

TC43 Acoustics (2012). Acoustics. Quantities and procedures for description and measurement of underwater sound from ships. Part 1: General requirements for measurements in deep water. Publicly Available Specification 17208-1, International Organization for Standardization.

Thomsen, F., Franck, D., and Ford, J. K. B. (2000). Characteristics of whistles from the acoustic 
1006

1007

1008

1009

1010

1011

1012

1013

1014

1015

1016

1017

1018

1019

1020

1021

1022

1023

1024 repertoire of resident killer whales (Orcinus orca) off Vancouver Island, British Columbia. Journal of the Acoustical Society of America, 109(3):1240-1246.

Tougaard, J., Wright, A. J., and Madsen, P. T. (2014). Cetacean noise criteria revisited in the light of proposed exposure limits for harbour porpoises. Marine Pollution Bulletin.

Tyack, P. L. (2008). Implications for marine mammals of large-scale changes in the marine acoustic environment. Journal of Mammalogy, 89(3):549-558.

UNCTD (2013). Review of maritime transport. United Nations Conference on Trade and Development, New York.

Urick, R. J. (1983). Principles of underwater sound, volume 3. McGraw-Hill New York.

Veirs, V. and Veirs, S. (2006). Average levels and power spectra of ambient sound in the habitat of Southern Resident orcas. NOAA/NMFS/NWFSC.

Wagstaff, R. A. (1973). RANDI: Research ambient noise directionality model. Technical report, DTIC Document.

Wales, S. C. and Heitmeyer, R. M. (2002). An ensemble source spectra model for merchant ship-radiated noise. The Journal of the Acoustical Society of America, 111(3):1211-1231.

Wenz, G. M. (1962). Acoustic ambient noise in the ocean: spectra and sources. Journal of the Acoustical Society of America, 34(12):1936-1956.

Williams, R., Erbe, C., Ashe, E., Beerman, A., and Smith, J. (2014). Severity of killer whale behavioral responses to ship noise: A dose-response study. Marine Pollution Bulletin, 79(1-2):254-260. 


\section{Figure 1 (on next page)}

Study site map 


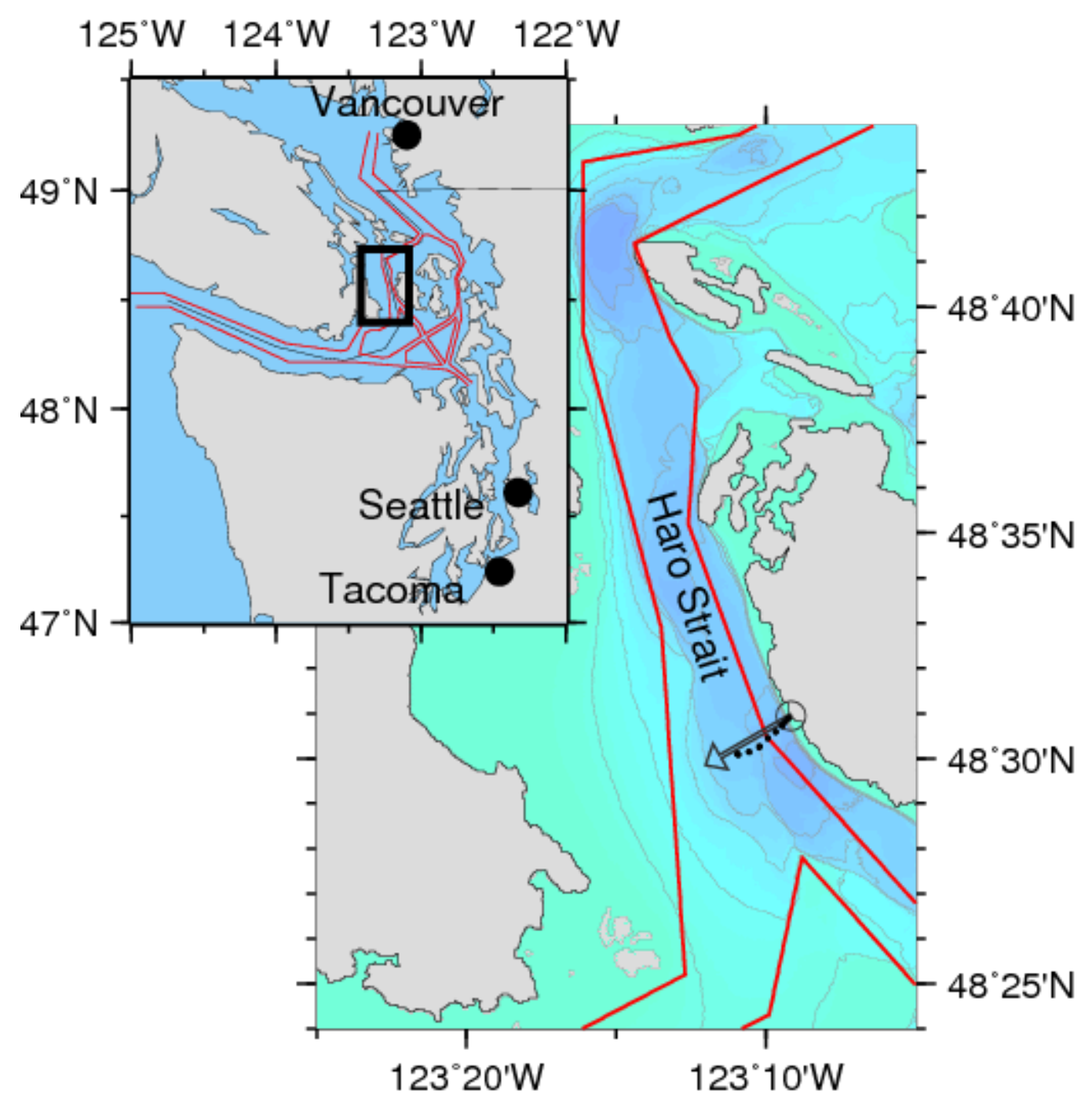


Figure 2 (on next page)

Comparison of source levels from different studies for various classes of ships 


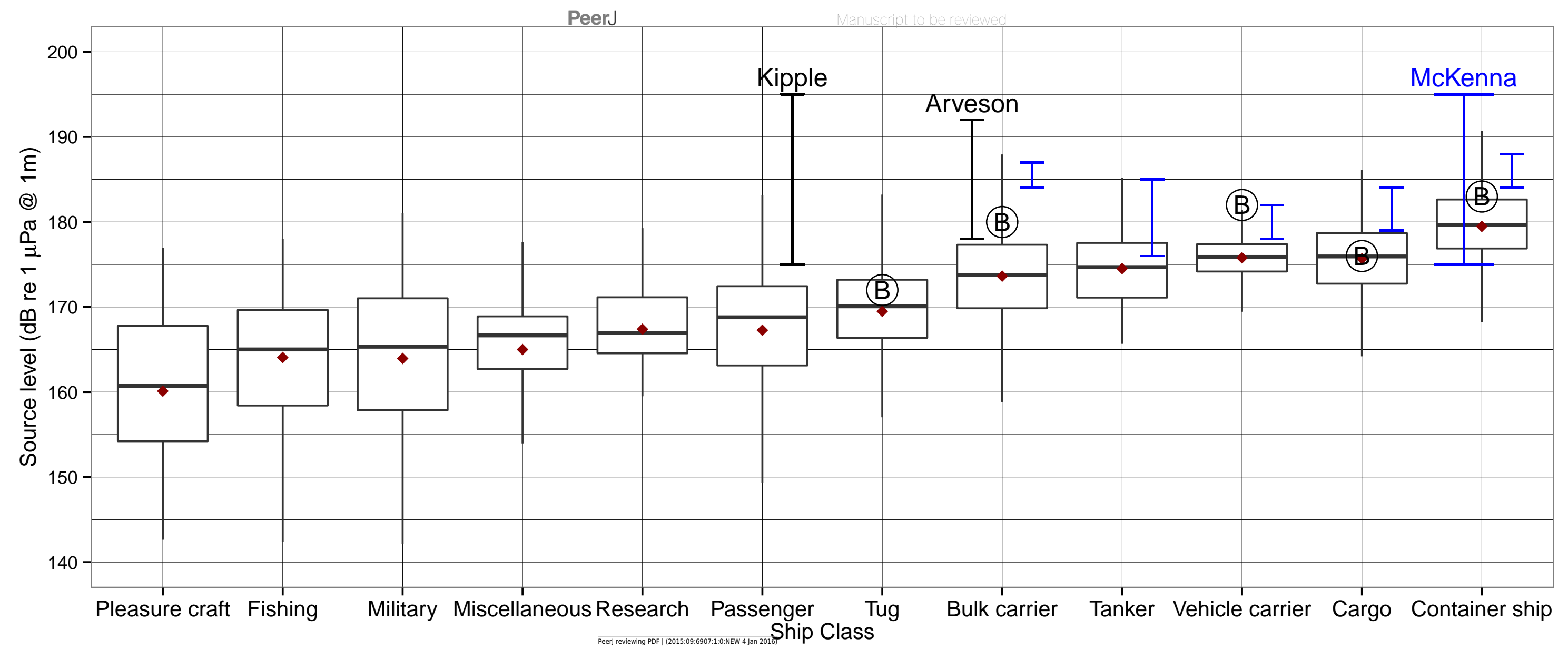


Figure 3 (on next page)

Quantiles of received spectra for background and ship noise 


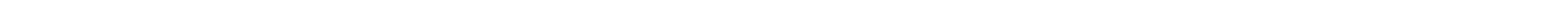


Figure 4 (on next page)

Ship noise source spectrum, 1/12-, and 1/3-octave levels 
Figure $\mathbf{5}$ (on next page)

Median source spectra of ship noise for different classes of ships 


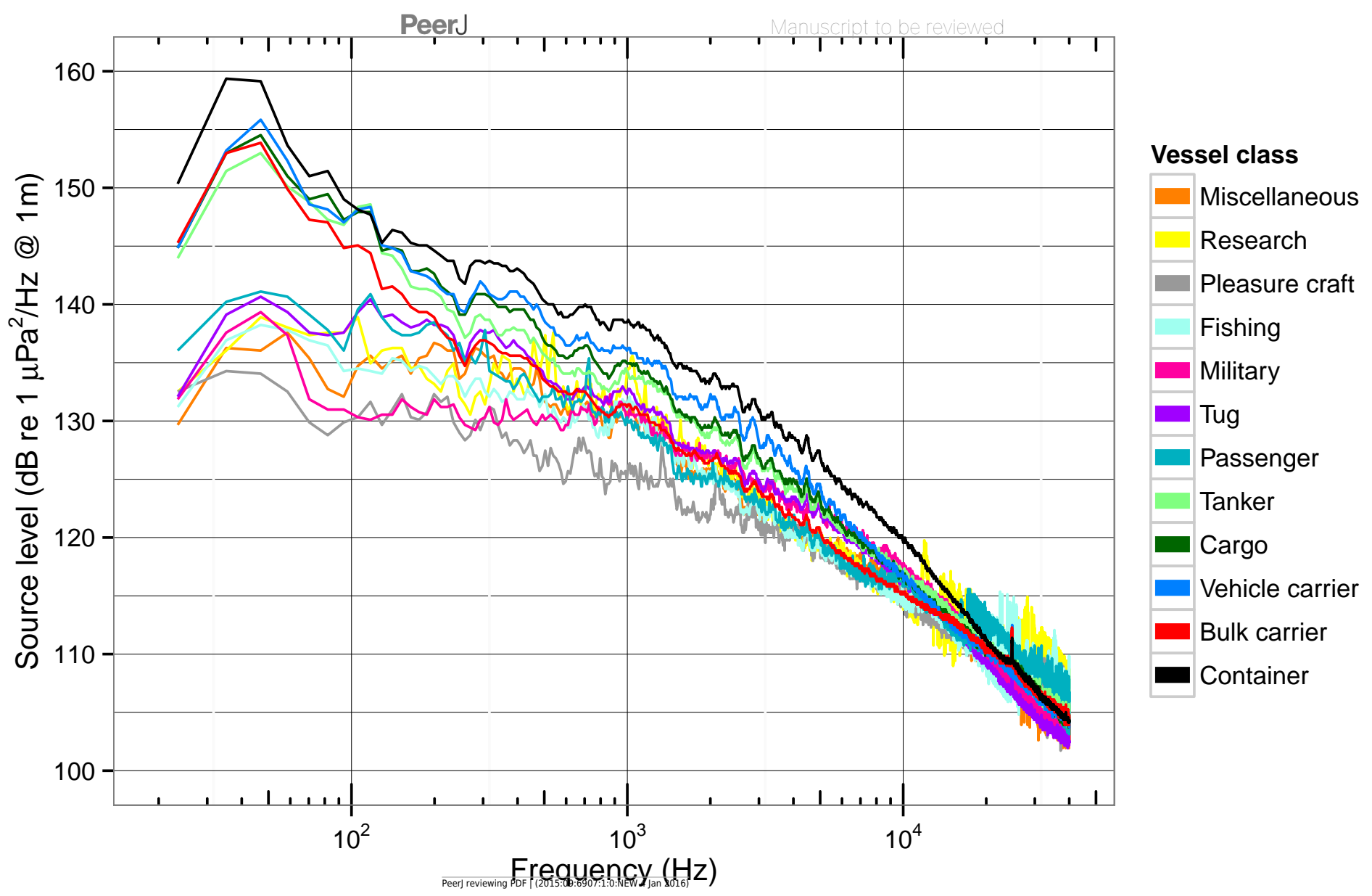


Figure $\mathbf{6}$ (on next page)

Quantiles of ship source spectra for different classes of ships 
